\title{
The competitive productivity $(C P)$ of tourism destinations: an integrative conceptual framework and a reflection on big data and analytics
}

Article

Accepted Version

Mariani, M., Bresciani, S. and Dagnino, G. B. (2021) The competitive productivity (CP) of tourism destinations: an integrative conceptual framework and a reflection on big data and analytics. International Journal of Contemporary Hospitality Management. ISSN 0959-6119 doi: https://doi.org/10.1108/IJCHM-09-2020-1102 Available at https://centaur.reading.ac.uk/98901/

It is advisable to refer to the publisher's version if you intend to cite from the work. See Guidance on citing.

To link to this article DOI: http://dx.doi.org/10.1108/IJCHM-09-2020-1102

Publisher: Emerald

All outputs in CentAUR are protected by Intellectual Property Rights law, including copyright law. Copyright and IPR is retained by the creators or other copyright holders. Terms and conditions for use of this material are defined in the End User Agreement. 


\section{www.reading.ac.uk/centaur}

\section{CentAUR}

Central Archive at the University of Reading

Reading's research outputs online 


\section{The Competitive Productivity (CP) of Tourism Destinations: An Integrative Conceptual Framework and a Reflection on Big Data and Analytics}

Purpose -The aim of this work is twofold. First, we elaborate an integrative conceptual framework of Tourism Destination Competitive Productivity (TDCP) by blending established destination competitiveness frameworks, the Competitive Productivity (CP) framework, and studies pertaining to Big Data and Analytics (BDA) within destination management information systems and smart tourism destinations. Secondly, we examine the drivers of TDCP in the context of the ongoing $4^{\text {th }}$ industrial revolution by conceptualizing the Destination Business Intelligence Unit (DBIU) as a platform able to create sustained destination business intelligence under the guise of BDA useful to support destination managers to achieve the tourism destination's economic objectives.

Design/methodology/approach - In this work, we leverage both extant literature (under the guise of research on competitive productivity, tourism destination competitiveness, destination management information systems) and empirical work (in the form of interviews and field work involving destination managers and CEOs of Destination Management Organizations and Convention Bureaus, as well as secondary data) to elaborate, develop, and present an integrative conceptual framework of Tourism Destination Competitive Productivity (TDCP).

Findings - The integrative conceptual framework of Tourism Destination Competitive Productivity (TDCP) elaborated has been found helpful by a number of destination managers trying to understand how to effectively and efficiently manage and market a tourism destination in today's fast-paced, digital, and hypercompetitive environment. While Destination Business Intelligence Units (DBIUs) are at different stages of implementation, often as part of broader smart destination initiatives, it appears that they are increasingly fulfilling the purpose of creating sustained destination business intelligence by means of BDA to help tourism destinations achieve their economic goals.

Originality - To the best of our knowledge, this study constitutes the first attempt to integrate the competitive productivity, tourism destination competitiveness, and destination management information systems research streams to elaborate an integrative conceptual framework of Tourism Destination Competitive Productivity (TDCP). Second, we contribute to the Industry 4.0 research stream by examining the drivers of tourism destination $\mathrm{CP}$ in the context of the ongoing $4^{\text {th }}$ industrial revolution. Third, we contribute to the destination 
management information systems research stream by introducing and conceptualizing the Destination Business Intelligence Unit (DBIU) and the related sustained destination business intelligence.

Research Implications/limitations - This work bears several practical implications for tourism policy makers, destination managers and marketers, technology developers, as well as tourism and hospitality firms and practitioners. Tourism policy makers could embed Tourism Destination Competitive Productivity (TDCP) into tourism and economic policies, destination managers and marketers might build and make use of platforms such as the proposed DBIU. Technology developers need to understand that designing destination management information systems in general and more specifically DBIUs requires an in-depth analysis of the stakeholders that are going to contribute, share, control and use BDA.

Keywords: Tourism destination competitiveness; Competitive Productivity (CP); Tourism destination; Big Data; Analytics; Business intelligence.

Paper type: Research paper 


\section{Introduction}

Firms and destinations are currently facing increasing levels of uncertainty and complexity in a fast-paced environment where achieving and maintaining a sustained competitive advantage even over short periods of time is progressively more difficult (D’Aveni et al., 2010). Recent scholarly and industry research has emphasized that Big Data and Big Data Analytics (BDA) are not only a critical underpinning technology of the Industry 4.0 phenomenon in manufacturing industries (Kagermann et al., 2013; Müller et al., 2018), but they are increasingly also a major driver of digital transformation of service industries (Akter et al., 2020; Mariani and Borghi, 2019) and a critical component of AI enabled services (Borghi and Mariani, 2020; Huang and Rust, 2018) in the tourism and hospitality verticals (Wirtz and Zeithaml, 2018).

Undeniably, Big Data and Analytics (BDA) are a critical component to achieve even a temporary advantage (D'Aveni et al., 2010) in an increasingly hypercompetitive global arena (D’Aveni, 1994). The role played by BDA for business intelligence has been illustrated and discussed in relation to a variety of industries, verticals and business functions (Davenport, 2014, 2017). More recently it has also been elaborated by looking specifically at travel, tourism and hospitality (e.g., Li et al., 2018; Mariani et al., 2018a; Mariani, 2019). However, the way business intelligence can translate into competitive advantage (Porter, 1985) and Competitive Productivity (CP) advantage (Baumann et al., 2019) in a digital and hypercompetitive world (D’Aveni, 1994) has been described in relation to tourism and hospitality firms, but not with regard to tourism destinations. Accordingly, the way tourism destinations can acquire a competitive advantage (Porter, 1980, 1985) and Competitive Productivity (CP) advantage (Baumann and Pintado, 2013) remains largely a terra incognita. This research gap is even more evident in light of the scholarly call for more studies on competitiveness and $\mathrm{CP}$ at the macro level (Baumann, Winzar, and Viengkham, 2019). Indeed, based on extant literature (e.g., Buhalis, 2000; Crouch and Ritchie, 1994, 1999; Mariani et al., 2014a; Mariani and Borghi, 2019) destinations at different level (supra-national, national and local) are fundamentally an amalgam of economic actors (be them individuals or firms) that are in competition with other destinations (Buhalis, 2000; Mariani and Baggio, 2012; Mariani et al., 2014b). For instance competition between country destinations has intensified significantly over the last seven decades: while in the 1950s the top ten destinations in terms of international tourist arrivals were controlling two thirds of the market and were concentrated in Europe, currently they control less than a third of the market and a number of emerging countries especially located in the Asia-Pacific region have become increasingly more competitive (UNWTO, 2019). 
More specifically, studies conceptualizing how Big Data BDA can be leveraged by tourism destinations and Destination Management Organizations (DMOs) to enhance their competitiveness in a sustained way while achieving productivity are missing. While a number of destination competitiveness frameworks have been advanced over time (Buhalis, 2000; Crouch, 2011; Crouch and Ritchie, 1994, 1999; Dwyer and Kim, 2003; Enright and Newton, 2004; Ritchie and Crouch, 2003), none of them has addressed how DMOs can leverage Big Data and BDA to empower DMOs' business intelligence and translate it into competitive advantage and possibly into $\mathrm{CP}$ advantage. To bridge this gap, this work combines three research strands - namely tourism destination competitiveness, Big Data Analytics for destination management and smart tourism destinations, and Competitive Productivity (CP) to make multiple contributions at the intersection of these three areas, and to elaborate an integrative conceptual framework of Tourism Destination Competitive Productivity (TDCP) and introduce the concepts of Destination Business Intelligence Unit (DBIU) and sustained destination business intelligence.

To make the aforementioned contributions, this study is organized as follows. In the second section we review extant literature in three research streams: tourism destination competitiveness frameworks; big data analytics for destination management and smart tourism destinations; competitive productivity. In the third section we elucidate the methodology. In the fourth section we introduce and elaborate an integrative conceptual framework of Tourism Destination Competitive Productivity blending destination competitiveness model, Big Data Analytics and the CP model. Moreover, we introduce, define, and elaborate the concept of Destination Business Intelligence Unit (DBIU). In the fifth and last section we draw our conclusions, synthesizing the distinctive features of our conceptual framework, identifying theoretical contributions and practical implications, and describing the limitations and a future research agenda.

\section{Theoretical background}

To shed light on the way tourism destinations nowadays can acquire a competitive advantage (Porter, 1980, 1985) and Competitive Productivity (CP) advantage (Baumann and Pintado, 2013), we review three research streams in a logical and chronological order: research on national and regional competitiveness and competitive productivity; tourism destination competitiveness frameworks; destination management information systems and big data analytics for destination management. We purposefully present and illustrate the three research 
streams in separate subsections for the sake of clarity and to guide the reader through the conceptual components that will be deployed to develop a comprehensive and overarching conceptual framework of Tourism Destination Competitive Productivity (TDCP). We start broadly by reviewing competitive advantage and Competitive Productivity (CP) studies (subsection 2.1); subsequently we narrow down and focus on competitive studies that have taken into account specifically tourism destinations (subsection 2.2) and later we link the stream of tourism destination competitiveness to an important driver of today's destination competitiveness: digital technologies and more specifically destination information systems and big data analytics.

\subsection{Competitive advantage and Competitive Productivity (CP)}

The study of competitive advantage has been one of the cornerstones of the management literature over the last four decades (e.g., Porter, 1985), because it is key to shed light on the processes leading to the creation of superior performance at a number of levels: organizational, regional and national. At the organizational level, an organization is said to possess a competitive advantage when: 1) its production cost is lower than those of its competitors (the so called cost advantage); 2) its customers are willing to pay a higher price (premium price) for its goods, compared to those of the competitors (the so called differentiation advantage) (Porter, 1980).

While in his seminal contribution Porter (1980) was referring specifically to organizations, later he has been enlarging the scope of his analysis to include nations by analyzing the competitive advantage of nations (Porter, 1990). In his work, he observes that companies based in certain nations are able to constantly outperform their counterparts based in other nations. He suggests that nations have four different attributes that, individually or as a system, represent the playing field that they operate for their industries. These attributes include: 1) factor conditions, which entail factors of production such as infrastructure and skilled labour; 2) demand conditions, which include the home-market demand for a specific product or service; 3 ) related or supporting industries that pertains to the presence of supplier industries or other related industries that display international competitiveness; 4) firms strategy, structure and rivalry that include how firms are started up, managed and organized in a nation. Each of the aforementioned elements influences how a firm can achieve international competitive success by leveraging superior skills and resources to identify and exploit business opportunities, with a view to achieving owners' and managers' goals and to innovating and creating business value. While the model has been critically assessed a number 
of times (e.g., Grant, 1991), some scholars have found it useful also to understand the competitiveness of smaller areas including regions (e.g., Porter, 2009; Tallmann et al., 2004) and cities (Porter, 1995).

More recently, by blending the rich tradition of competitiveness studies (Porter, 1985, Grant, 1991) and the notion of productivity, Baumann and Pintado (2013) have introduced and elaborated the concept of Competitive Productivity (CP), whereby CP is defined as "an attitude and behaviour directed at beating the competition through pragmatism" (Baumann and Pintado, 2013: 9). In its original formulation, CP is understood as characterized by six different components: benchmarking (i.e., CP benchmarks performance against industry leaders to aspire to the same or higher market position); culture (i.e., CP is a culture focusing on performance and competitiveness); education/development (i.e., CP revolves around performance orientation infused in the education system); environment/infrastructure (i.e., CP contributes to creating and upgrading a country's or firm's infrastructure); performance (i.e., $\mathrm{CP}$ engenders high-quality value propositions); values (i.e., $\mathrm{CP}$ entails a positive mindset and service attitude).

In their most recent work, and departing from the original definition formulated by Baumann and Pintado (2013), Baumann et al. (2019) argue that CP can be conceptualized at three different levels (macro, meso and micro) to appreciate differences when observing a nation, a firm or an individual. More specifically, at the macro level, the National Competitive Productivity (NCP) is defined as "both an attitude and behaviour directed at outperforming competing nations, and past performance through pragmatism" (Baumann et al., 2019: 124). At the meso level, Firm Competitive Productivity (FCP) is defined as "both an attitude and behaviour directed at outperforming the competing firms, and past performance through pragmatism" (Baumann et al., 2019: 124). At the micro-level, Individual Competitive Productivity (ICP) is defined as "both an attitude and behaviour directed at outperforming the competing individuals, and past performance through pragmatism" (Baumann et al., 2019: 124). A number of empirical studies are emerging with the aim to test parts of the $\mathrm{CP}$ concept in a number of industries and with different methods (e.g., Baumann et al., 2021; Chen and Lin, 2020; Hoadley, 2020).

Perhaps the most relevant conceptualization of $\mathrm{CP}$ in relation to tourism destinations is the one related to the macro level, as destinations are complex ensembles of "resources", "situational conditions", "destination management", and "demand conditions" (Dwyer \& Kim, 2003) that transcend the borders of an individual firm. Accordingly, the most suitable nuance of $\mathrm{CP}$ in the context of tourism destination management is the National Competitive 
Productivity (NCP). Baumann et al. (2019) explain that the main drivers of the National Competitive Productivity (NCP) entail political stability, geography, culture, and economic policies. Moderating variables include situation, context, location and time. The framework developed by Baumann et al. (2019) is illustrated in the following Figure:

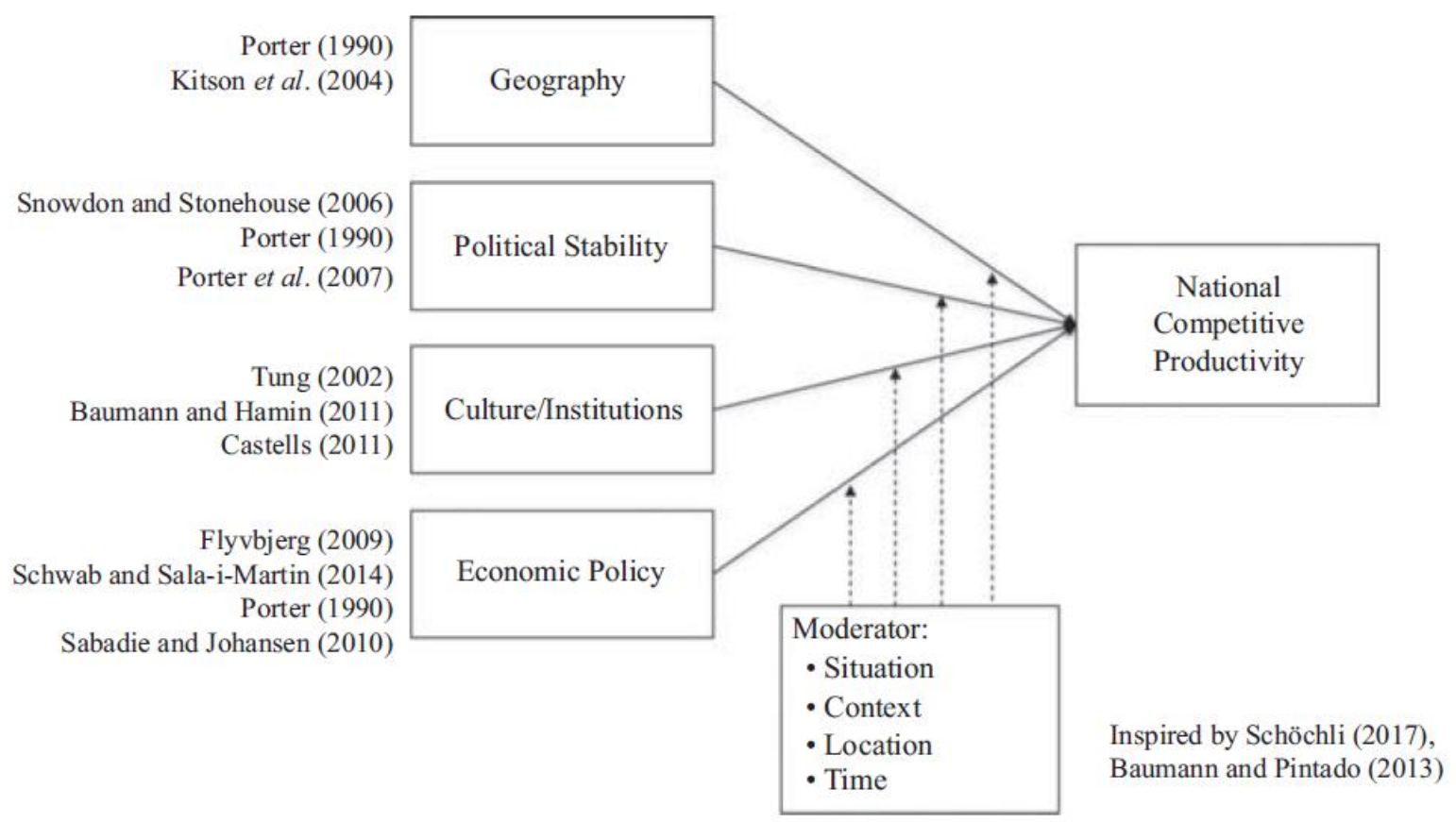

Figure 1. National Competitive Productivity (NCP) model. Source: Baumann et al. (2019).

An element which is clearly (and surprisingly) missing from this framework is the ensemble of technologies brought about by the 4th industrial revolution (Kagermann et al., 2013; Müller et al., 2018), and a reflection on the role that data and big data play as the necessary oil (Economist, 2017) for these technologies to work and perform well. Arguably this represents a significant omission as today's national competitiveness and productivity are significantly reliant on digital technologies and data in both developed and developing countries (Economist, 2018). This is the reason why a high and increasing number of national and supranational governments have endowed themselves with industrial plans such as the Industrie 4.0 in Germany (2011), the Industrie du Future in France (2013), the Factories of the Future at the European level (2014), the Internet Plus in China (2015), the Fabbrica Intelligente in Italy (2016), etc (Müller et al., 2018). All these industrial plans explicitly recognize digital technologies (including Big Data and Analytics) as the way forward for countries and nations to gain success and competitiveness in both manufacturing and services in the digital era 
(Kagermann et al., 2013; Müller et al., 2018). However, thus far, no study in the National Competitive Productivity (NCP) domain has closely examined the role of digital technologies (including Big Data and Analytics) for the CP of a nation in general and of a tourism destination in particular. Moreover, no study has introduced or proposed an integrative conceptual model to illustrate if and to what extent $\mathrm{CP}$ is relevant for tourism destinations. Extant scholars have mostly focused on elaborating destination competitiveness models that are illustrated critically in the following subsection.

\subsection{Tourism destination competitiveness}

Destination competitiveness, as a specific subfield of destination management studies, has been significantly examined starting from the second half of the 1990s (e.g., Crouch \& Ritchie, 1999; Pearce, 1997). In keeping with a long tradition of destination image research (Enright and Newton, 2004), the pioneering studies on destination competitiveness have been developed by Crouch and Ritchie $(1995,1999)$ who elaborated a conceptual model of tourism destination competitiveness (TDC), based on Porter's (1990) popular "diamond of national competitiveness" framework. Porter's framework assumes that a nation might achieve a competitive advantage in a focal industry vis-à-vis its counterparts if it displays strengths in the following four elements: factor conditions, demand conditions, related and supporting industries and firms' strategy, structure and rivalry. Any of the aforementioned drivers of competitiveness can be influenced by chance events and government. Drawing on Porter's (1990) framework, Crouch and Ritchie (1999) suggest that factor conditions (both inherited and created) are an important driver of competitiveness for tourism destinations. Demand conditions, especially domestic demand, are critical for a tourism destination and in many cases "most national tourism industries depend upon domestic tourism demand for the majority of their business" (Crouch and Ritchie, 1999: 141). Related and supporting industries in a tourism destination include retailing, leisure and recreation, entertainment industries. Regarding firm strategy, structure, and rivalry, a climate of competition between tourism firms within a destination can be observed. Chance events (such as the outbreak of a deadly virus, environmental catastrophes, terrorist attacks) and the government (such as introducing foreign exchange restrictions) can influence the tourism demand and supply.

Eventually, Crouch and Ritchie (1999) developed their tourism destination competitiveness (TDC) framework suggesting that the competitiveness of a destination is dependent on four sets of factors: "core resources and attractors", "supporting factors and resources", "destination management", and "qualifying determinants" that are influenced by 
the micro and macro environment (see Figure 2). The core resources constitute the key drivers to visit a destination and entail elements falling in six categories: physiography, culture \& history, market ties, activities, events, and the tourism superstructure. The supporting factors and resources represent the factors upon which a successful tourism industry is built and entail the destination's infrastructure, various facilitating resources including the public service, education, financial institutions, the entrepreneurial system, and the destination accessibility. The destination management revolves around activities enhancing the appeal of core resources that strengthen the effectiveness of the supporting factors: it encompasses the marketing of the destination, the quality of service and experience, the effective use of information systems assisting destination managers to understand visitors' needs and product development, the leadership in destination management by means of a Destination Management Organization (DMO), and resource stewardship. The qualifying determinants, which can be defined as situational conditions, include location, dependencies, safety and cost and can moderate or mediate the effect of the other three groups of factors (i.e., core resources, supporting factors and destination management). To sum up, by adding supporting factors, destination management and qualifying determinants to tourism-specific factors captured in the core resources and attractors, Crouch and Ritchie's (1999) framework advances previous analyses that developed models of the tourist product or destination image (Enright and Newton, 2004).

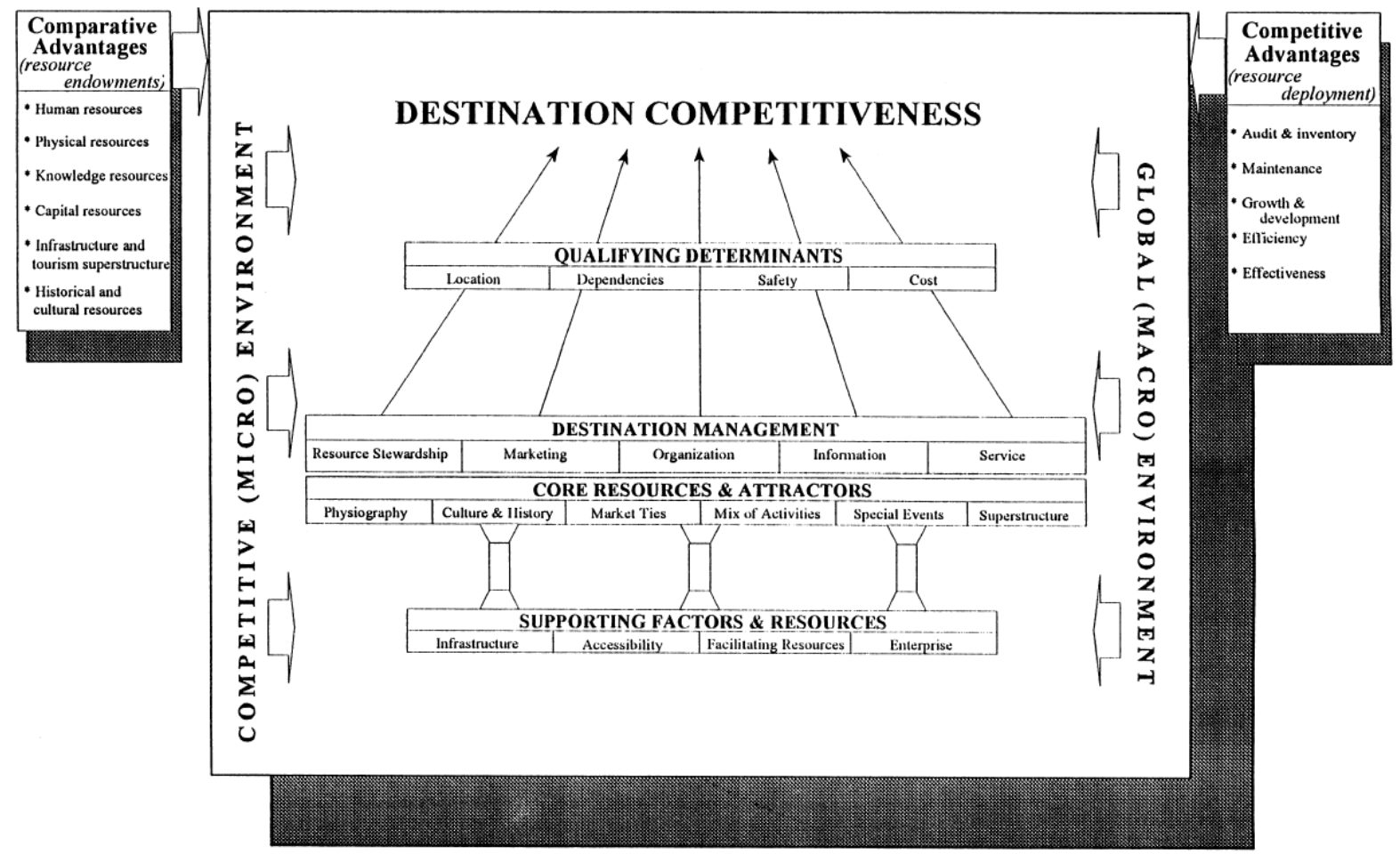

Figure 2. Conceptual model of Tourism destination competitiveness (Crouch and Ritchie, 1999) 
Bringing together the factors included in Porter's (1990) popular "diamond of national competitiveness" framework and the main elements of destination competitiveness proposed by Crouch and Ritchie (1995, 1999) and Ritchie and Crouch (1993, 2000), Dwyer and Kim (2003) develop an integrative framework of destination competitiveness,. The model proposed by Dwyer and Kim (2003) recognizes demand conditions as an important determinant of destination competitiveness and suggests that the latter is only an intermediate goal of policy making to achieve higher levels of national/regional prosperity. In their model, Dwyer and Kim (2003) suggest that the competitiveness of a destination is dependent on four sets of factors: "resources", "situational conditions", "destination management", and "demand conditions" (see Figure 3).

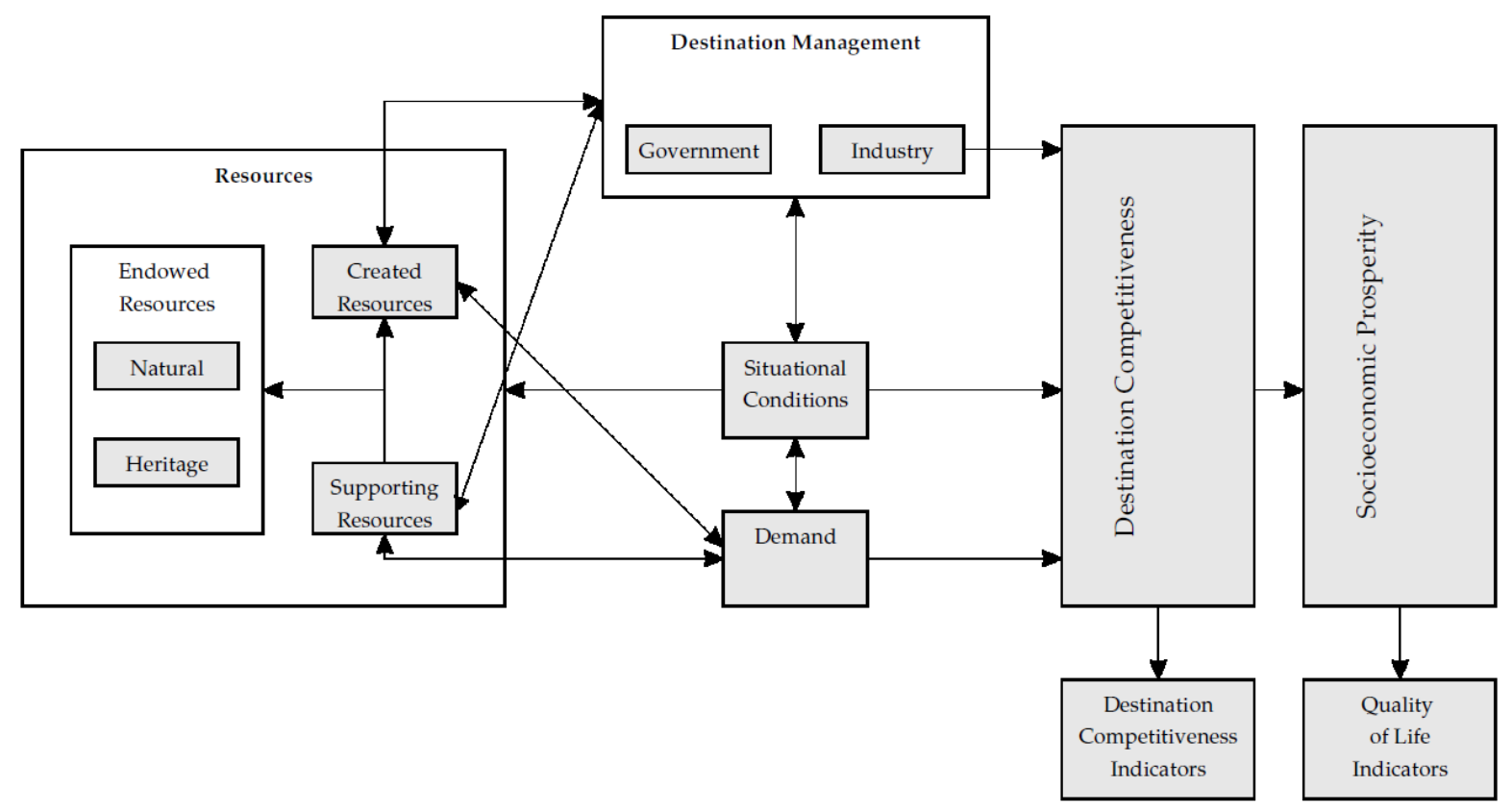

Figure 3. An integrative conceptual model of tourism destination competitiveness (Dwyer and Kim, 2003)

Resources fall into two categories: endowed (inherited) and created. The former ones consist of natural (including beaches, lakes, mountains, rivers, etc.) and heritage (including monuments, language, gastronomy, customs, handicrafts, etc.). The latter ones entail infrastructure, entertainment activities, shopping and special events. Supporting Resources encompass the quality of service, general infrastructure, accessibility of the destination, 
hospitality and market ties. Also in this competitiveness model, like in Crouch and Ritchie's (1999) tourism destination competitiveness framework, the supporting resources assist the destination to leverage more effectively the core resources (be them endowed or created). Situational Conditions include socio-economic, demographic, cultural, political, legal, environmental, governmental, competitive, technological, regulatory, and other trends that influence how organizations located in the destination do business. Generally, the situational conditions fall either in the operating environment (Porter, 1980, 1990) or the remote environment (Tribe, 1999). Destination Management factors entail the activities of destination management organizations (DMOs), destination marketing, destination policy, planning and development, human resource development and environmental management (Ritchie \& Crouch, 2000). In this framework, Dwyer and Kim (2003) distinguish between destination management carried out by the public vs. the private sector: the former one deals with national tourism strategies, National Tourism Organization (NTO) marketing, environmental protection legislation; the latter one pertains mainly to initiatives of tourism/hospitality industry associations co-funding destination marketing programs, industry training programmes, etc. In line with Crouch and Ritchie (1999), the destination management activities can improve the appeal of core resources and strengthen the effectiveness of the supporting resources. Last, the model includes demand conditions which entail three elements: tourism demand-awareness, perception and preferences. A destination's product should be developed in such a way that it should target the evolving consumer needs and preferences, to increase the destination competitiveness. The model encompasses both uni-directional and bi-directional arrows that indicate how each element of the model influences the others.

So far, we have been discussing models of destination competitiveness without explicitly taking into account the paramount role that technologies - especially digital technologies - have played in the development of tourism over the last forty years (Buhalis \& Law, 2008; Mariani et al., 2014b). Since the moment (beginning of 2000) when the most dominant frameworks of destination competitiveness were developed, much has changed in the technological landscape. Today both production and consumption of tourism products, services and experiences have profoundly changed due to the emergence and consolidation of digital technologies that are used strategically by tourism destinations and firms. In the current digital landscape, destinations are endowed with sensors and intelligent systems that are capable to collect, store, process and analyze large volumes of data (i.e., big data) to inform operations, services and innovation processes, and ultimately make destinations "smart" (Gretzel et al., 2015). Among the wide range of digital technologies currently in use, big data 
have been found particularly relevant to derive knowledge (Li et al., 2018) and intelligence (Mariani et al., 2018a) at the core of smart destination initiatives. Moreover, a few scholars seem to implicitly suggest that big data might potentially enhance the competitiveness of smart destinations (Gretzel et al., 2015).

In the illustration of their model, Crouch and Ritchie (1999) mention technology only five times in total, either in a generic way or in relation to the "levels of competition" (p. 141) and the "technology-human resource interface" (p. 146), without further explanations. Accordingly, the role of technology is not sufficiently elaborated in their model. In the description of their model, Dwyer and Kim (2003) mention more often technologies, but only in a couple of occasions they focus on the predecessors of Industry 4.0 technologies, namely ICTs and they observe that "Taking advantage of new technologies and the Internet can also enable destinations to enhance their competitiveness" (Dwyer and Kim, 2003: p. 396). Interestingly, Dwyer and Kim (2003) suggest that technologies are important, but do not dig deeper on the potential that they could have to ensure both the competitiveness and productivity of a tourism destination. In other terms they do not make explicit that digital technologies in the context of a digital transformation can be an important driver of tourism destination $\mathrm{CP}$, perhaps also because at the time their model was produced scholarly and industry research had not yet reached a maturity in the area of digital transformation and Industry 4.0 technologies. This represent a research gap in extant tourism destination competitiveness models. Indeed, despite an increasing body of scholarly and industry research has emphasized that BD and analytics among the digital technologies underpinning the 4th industrial revolution (Kagermann et al., 2013; Müller et al., 2018) can propel the competitiveness of entire nations and regions and enhance the productivity of entire industries, extant tourism destination competitiveness research does not highlight explicitly the role of Industry 4.0 technologies for tourism destination competitive productivity. Accordingly, and with the intention to embed more explicitly Industry 4.0 technologies and more broadly digital technological factors into destination competitiveness frameworks, in the next subsection we review the literature related to the role of big data in destination management.

\subsection{Big Data and Big Data Analytics for destination management and innovation, and smart tourism destinations}

Recent scholarly and industry research has emphasized that Big Data and Big Data Analytics are not only an underpinning technology of the Industry 4.0 in manufacturing industries (Kagermann et al., 2013; Müller et al., 2018), but increasingly a major driver of digital 
transformation of service industries (Akter et al., 2020; Mariani and Borghi, 2019; Mariani, 2019) and a critical component of AI enabled services (Huang and Rust, 2018) in the tourism and hospitality verticals (Wirtz and Zeithaml, 2018). Undeniably, Big Data are a critical component to achieve even a temporary advantage (D’Aveni et al., 2010) in an increasingly hypercompetitive global arena (D’Aveni, 1994) such as tourism.

Traditionally, the "big data" notion appeared in the late 1990s in the computer science literature concerning scientific visualization (Cox \& Ellsworth, 1997). Yet, its first definition with relevant prominence in the management domain was formulated 20 years ago by Doug Laney, who acknowledged and described the three main characteristics of big data termed as the 3Vs (Laney, 2001): Volume (dimension of data, currently in the order of zettabytes), Velocity (swiftness of data generation, modification, and transfer), and Variety (data materialize in different formats). Subsequently, scholars perfected the earlier definition by introducing the Vs of Veracity (the reliability of data), and Value (the process of extracting business insights from data by means of analytics), thus leading to the formulation of a $5 \mathrm{Vs}$ framework (Fosso Wamba et al, 2015; Mariani and Fosso Wamba, 2020).

The general business literature has identified dozens of sources of big data ranging from financial and non-financial online transactions, online information searches, information diffusion on digital platforms, and social interactions through online review platforms and social networking sites (Blazquez \& Domenech, 2018). Recent research in tourism and hospitality (Li et al., 2018) has identified a wide variety of sources including devices in the guise of device data (e.g., mobile roaming data, Wifi data, GPS data, etc.), operations under the guise of transaction data (e.g., online booking data, web search data, etc.) and user data in the form of user generated content (UGC) data (e.g., online picture and text data). Conceivably, the most popular form of data in tourism settings is UGC data that entails social media posts and online reviews, that have been extensively used to gain a better understanding of customer experience, engagement and satisfaction with hospitality services (e.g., Marianiet al., 2020; Mariani et al., 2018a; Xiang et al., 2015) and tourism destinations (e.g., Mariani et al., 2018b; Marine-Roig \& Anton Clavé, 2015) in online settings.

However, big data per se are not sufficient. Interestingly, big data allows entrepreneurs and companies to generate Big Data Analytics (BDA), which can be defined as "a holistic process that involves the collection, analysis, use, and interpretation of data for various functional divisions with a view to gaining actionable insights, creating business value, and establishing competitive advantage" (Fosso Wamba et al., 2020). In general, BDA have been found to enhance business intelligence, thus assisting entrepreneurs and managers to optimize 
inventories, enhance customer satisfaction, identify target customer segments, streamline operations, and manage supply chain risks effectively (Davenport, 2014, 2017; Mariani and Matarazzo, 2020). Such actions are conducive to superior levels of organizational performance, innovation performance, as well as competitive advantage (Mariani and Fosso Wamba, 2020; Nam et al., 2019).

The role played by BDA for business intelligence in tourism and hospitality firms has been discussed in a number of studies (for a literature review see Mariani et al., 2018a). However, the way big data can generate business intelligence and translate into competitive advantage (Porter, 1985) for tourism destinations is seriously under-researched. Only recently a new way of conceiving and using information and communication technologies (Ivars-Baidal et al., 2019) and digital technologies in destination management has emerged. For instance, Fuchs et al. (2014) developed a Destination Management Information System for the Swedish destination of Åre (DMIS-Åre). The system consists of three sets of indicators that are the outcome of Big Data analytics and entail: 1) economic performance indicators; 2) customer behavior indicators; and 3) customer perception and experience indicators. The first set of indicators includes prices, reservations, hotel overnights, and so on. These indicators are complemented with data about users' behavior, including web navigation behaviors before reservations. Customer analytics can be used to tailor personalized offers and analyze trends. The third set of indicators includes information about users' perception of destinations' attractiveness.

More recently, the research stream revolving around smart tourism destinations and smart cities has underscored the importance of Big Data and analytics to effectively manage and market tourism destinations and to inform operations, services and innovation processes, at the destination level (e.g., Bakıcı et al., 2013; Batty, 2013; Becken et al., 2019; Gajdošík, 2019; Gretzel et al., 2015; Shao et al., 2017; Wise \& Heidari, 2019; Xiang et al., 2015; Zeng et al., 2020). "Smart tourism" has been described as "a distinct step in the evolution of ICT in tourism in that the physical and governance dimensions of tourism are entering the digital playing field, new levels of intelligence are achieved in tourism systems" (Gretzel et al., 2015: 180) as the ways in which tourism experiences are created, consumed and shared are different. For instance, Shao et al. (2017) illustrate how big data from travel blogs on Huashan (China), can assist destination managers to learn about travel behaviors. The authors mine data about the destination from travelers' UGC created on the Ctrip and Mafengwo websites. By using semantic analysis, the researchers were able to identify tourist movement patterns and GIS provided a visual distribution of the bloggers' origin. The results generated insights for 
destination managers on how to implement destination planning and design in the selected Chinese scenic area.

Based on the state-of-the art technologies applied in tourism destinations, Gajdošík (2019) develop a novel conceptual model of intelligent information system for smart tourism destinations by identifying the requirements on information systems. The proposed model consists of three layers - data collection, processing and exchange. Data collection includes personal, behavioral, geographical and other data. The data processing layer consists of realtime processing of all collected data. Last, the data exchange layer entails open data allowing information sharing among tourism stakeholders, and data are made available through extranet and support the "soft smartness" of a destination. By conducting a qualitative study on the smart tourism initiative led by the city government of the Chinese city of Qinhuangdao, Zeng et al. (2020) share an understanding of the role of Big Data analytics for the smart destination. They find that there is a sequence of stages from "Smart Decision" to "Smart Development" to "Smart Destination", each of them characterized by a number of different technological affordances. In the "Smart decision" stage, organizational actors try to perform descriptive analysis to explore the feasibility of their smart tourism initiative by means of APIs, data lakes and visualization. In the "Smart development" stage, the organizational actors integrated different data and technologies to perform diagnostic and predictive analysis, with a clear goal to improve existing tourism services, by deploying stream, web and social media analytics. In the "Smart Destination" stage, a number of interdependent groups of actors appropriated different features of BDA technologies to execute prescriptive analysis relevant for strategic decisions.

In summary, the review of the literature pertaining to Big Data analytics in tourism clearly shows that BDA - as a component of digital technologies - have not been conceptualized explicitly as (technological) drivers of tourism destination competitiveness. This represents clearly a major research gap that our paper will try to bridge by developing an integrative conceptual framework of tourism destination competitive productivity.

\section{Methodology}

In line with the conceptual work describing destination competitiveness developed by Crouch and Ritchie (1999), also in this paper we adopt a conceptual approach and develop a model stemming from the coalescence of a number of research projects and activities carried out over the last decade. The elaboration of the conceptual framework evolved inductively over time 
and starts with a few basic assumptions that are rooted in the established destination competitiveness literature (Crouch and Ritchie, 1995, 1999; Dwyer \& Kim, 2003). The concept behind the model emerged from the ground, in line with the grounded research approach (Glaser and Strauss, 1967) adopted also by Crouch and Ritchie (1999). More specifically, this involved: 1) researches by the authors on destination management and marketing and big data analytics conducted before $2019 ; 2$ ) the elaboration of feasibility and strategic plans for Destination management Organizations and Convention Bureaus of three cities in Europe; 3) the contribution with a keynote speech to a conference on the reform of the regional law for tourism in a European region and an additional keynote for the NTO of a European country; 4) continued interaction with a group of more than 50 destination manager and Convention and Visitor Bureau managers over the last 7 years (several of them were met at major travel trade conferences and fairs such as ITB Berlin, WTM London, Fitur Madrid, MITT Moscow, Salon Mondial du Tourisme Paris, and other public or private events); 5) confidential information deriving from advisory activities involving 4 DMOs (3 at city level and one at national level) and 3 Convention Bureaus ( 2 at local level and 1 at national level) in Europe; 6) a series of conference call interviews lasting from 45 to 100 minutes with CEOs and managers of relevant and large European DMOs, some of them included under the umbrella of the European Cities Marketing association; 7) feedback, debate and introspection stemming from papers on the topic of destination management, destination management information systems, ICTs and tourism destinations, big data and big data analytics, smart tourism destinations, presented in a number of conferences including the ENTER conference, the reference conference organized by the International Federation for Information Technologies and Travel \& Tourism and other main international conferences hosting tracks on destination management competitiveness, smart destinations and big data analytics and business intelligence; 8) further conversations with CVB participants attending a Master in Destination Management in a leading university; 9) secondary data collected by reviewing articles that have examined the adoption of big data analytics in tourism destinations. The qualitative research entailing the interactions mentioned in 5) and the interviews mentioned in 6) constituted a significant stage in the evolution of the model. The following interview guide was deployed in relation to 6):

1) In your opinion, what are the major drivers of destination competitiveness in today? What is the role played by these drivers?

2) In your opinion, what is the role played by technologies as drivers of destination competitiveness today?

3) What criteria and indicators are you using in evaluating destination competitiveness? 
4) Are competitiveness factors different for different markets?

5) What are the major strengths in your destination?

6) Can you list tourism destinations that you think are very competitive? In your opinion what makes them so competitive?

7) What is the role of technologies in driving destination competitiveness? What technologies are more relevant to guide destination competitiveness?

8) What are the main drivers of "cost" of a tourism destination?

9) How important is productivity in determining the cost of destination-related services and ultimately their competitiveness?

10) Can you list tourism destinations that you think have lower costs? In your opinion what allows them to keep a cost advantage?

11) How do stakeholders responsible for the competitiveness of a tourism destination maintain and enhance their competitiveness in the long and short term?

The findings from the interviews and aforementioned activities were triangulated with secondary data from empirical studies published in major tourism and hospitality journals as well as information systems and computer science journals (e.g., Fuchs et al., 2014; Zeng et al., 2020).

The resulting model is developed in section 4. The conceptual model is not causal, deterministic or predictive. Rather, in line with extant framework of destination competitiveness (e.g., Crouch and Ritchie, 1999; Dwyer \& Kim, 2003) it is illustrative and has the mere purpose of explaining the forces underlying tourism destination competitive productivity. In its current version, the framework can be described as a "theory on a topic" (Neuman, 2007) and thus it is intentionally abstract and does not relate to a specific tourism destination in particular. Indeed, the attempt here is to generalize as much as possible.

\section{An integrative conceptual framework of Tourism Destination Competitive Productivity}

Based on the literature reviewed and the extensive work carried out with destinations over the last decade, we are now able to develop an integrative framework blending the tourism destination competitiveness framework elaborated by Dwyer and Kim (2003), the Competitive Productivity (CP) framework proposed by Baumann et al. (2019) and theory and research related to the role of Big Data and Big Data Analytics in the context of information management systems (e.g., Fuchs et al., 2014; Benckendorff et al., 2014) and smart destination 
systems (e.g., Gretzel et al., 2015). Overall, this allows us to conceptualize a novel CP-related paradigm of tourism destination competition. In this paradigm, destination competitiveness is drawn from the research stream on tourism destination competitiveness (e.g., Crouch and Ritchie, 1999) and, consistently with recent research (Van Reenen, 2011), we assume that competition raises productivity through improving management quality. This holds at a destination level, especially when nearby destinations compete with each other (Mariani et al., 2014a). Accordingly, we hypothesize that the more nearby destinations enhance their competitiveness (by leveraging also on destination business intelligence and the related BDA), the higher will be destination management quality, which will translate into increased productivity.

The integrative conceptual framework - illustrated in Figure 4 - consists of six major groups of drivers that constitute its building blocks:

- the government (Dwyer \& Kim., 2003);

- the drivers of $C P$ at the macro level inclusive of geography, political stability, culture/institutions and economic policy (Baumann et al. 2019);

- the destination's resources which can be described as endowed, created and supporting (Dwyer \& Kim., 2003);

- demand conditions (Dwyer \& Kim., 2003);

- $\quad$ situational conditions (Dwyer \& Kim., 2003);

- destination management (Crouch and Ritchie, 1999; Dwyer \& Kim., 2003) empowered by a Destination Business Intelligence Unit (see section 4.1).

How do these elements relate to each other in this integrative framework? The Government (at any level: national and local) plays a key role as it has the capability to influence political stability, cultural institutions, and economic policies at the destination level. For instance, national (and local) governments are in charge of fiscal policies that can significantly affect the tourism destinations CP. For instance, an executive of a Spanish DMO underlined that:

"Over the last years the government has offered tax incentives in the form of $R \& D$ tax credits allowing hotels and other tourism and hospitality firms - including agritourism firms - to claim capital allowances for money spent on construction costs, including building, refurbishment, and fitting out of buildings, as well as improving business processes. Tourism firms can claim $30 \%$ or more of expenditure up to a certain amount in 
an accounting period. Overall, these incentives have not been adopted by every business, but those businesses which adopted them were able to improve the quality of their facilities in an efficient way. I have read the results of a survey on local accommodation providers in 2017, and realized that those businesses that accessed the tax credits also experienced a dramatic increase in bookings, reservations, and revenues and customers' evaluations of their facilities improved significantly overall. It is very likely that those enterprises have become more profitable because revenues have increased more than costs due to increased efficiency and tax incentives" (Destination manager, Spanish destination).

However, culture and political stability outside the focal destination might in their turn affect the government. The government exerts its influence also on destination management by influencing how the Destination Management Organization (DMO) is structured and staffed, thus directly and indirectly shaping smart tourism destination initiatives, and part of the big data initiatives carried out by the Destination Business Intelligence Unit. It also affects the "created resources" consisting of tourism infrastructure which includes hospitality and accommodation facilities, transportation means, food and restaurant services, themed attractions, tour operators, convention and visitor bureaus as well as additional ancillary services (Crouch and Ritchie, 1999; Dwyer and Kim, 2003). Last, it influences also the tourism industry at the destination level, through laws and regulations.

In line with the framework of $C P$ at the macro level (Baumann et al. 2019), also in the framework of Tourism Destination CP, geography, political stability, culture/institutions and economic policy play a significant role. More specifically, geography influences directly Destination CP but also indirectly by affecting the Endowed Resources in particular (and the Resources in general). Political stability, culture/institutions and economic policy play the role of mediators between Government and destination CP. Indeed, interaction with European destination managers and tourism experts made it apparent that in several European countries (including Switzerland, the UK, France, Spain) national and local governments - as well as private institutions - support significantly professional education in the hospitality and tourism field and this translates into enhanced levels of skilled labor force and managers that are critical to improve the efficiency and effectiveness of the organizations they work for, and ultimately the destination CP and competitiveness.

The destination's resources which can be classified as endowed, created and supporting (Dwyer \& Kim., 2003) influence the government, destination management as well as demand. Indeed, the resources are a key pull factor for visitors and, by increasing tourism demand, they 
enhance the tourism destination CP. By developing "created resources" such as venues able to host meeting and events, Germany, France, Spain, the UK, Italy, Netherlands and Portugal in Europe have been able to boost their capacity to deal with events effectively and efficiently as mentioned by two executives of CVBs members of the International Congress and Convention Association.

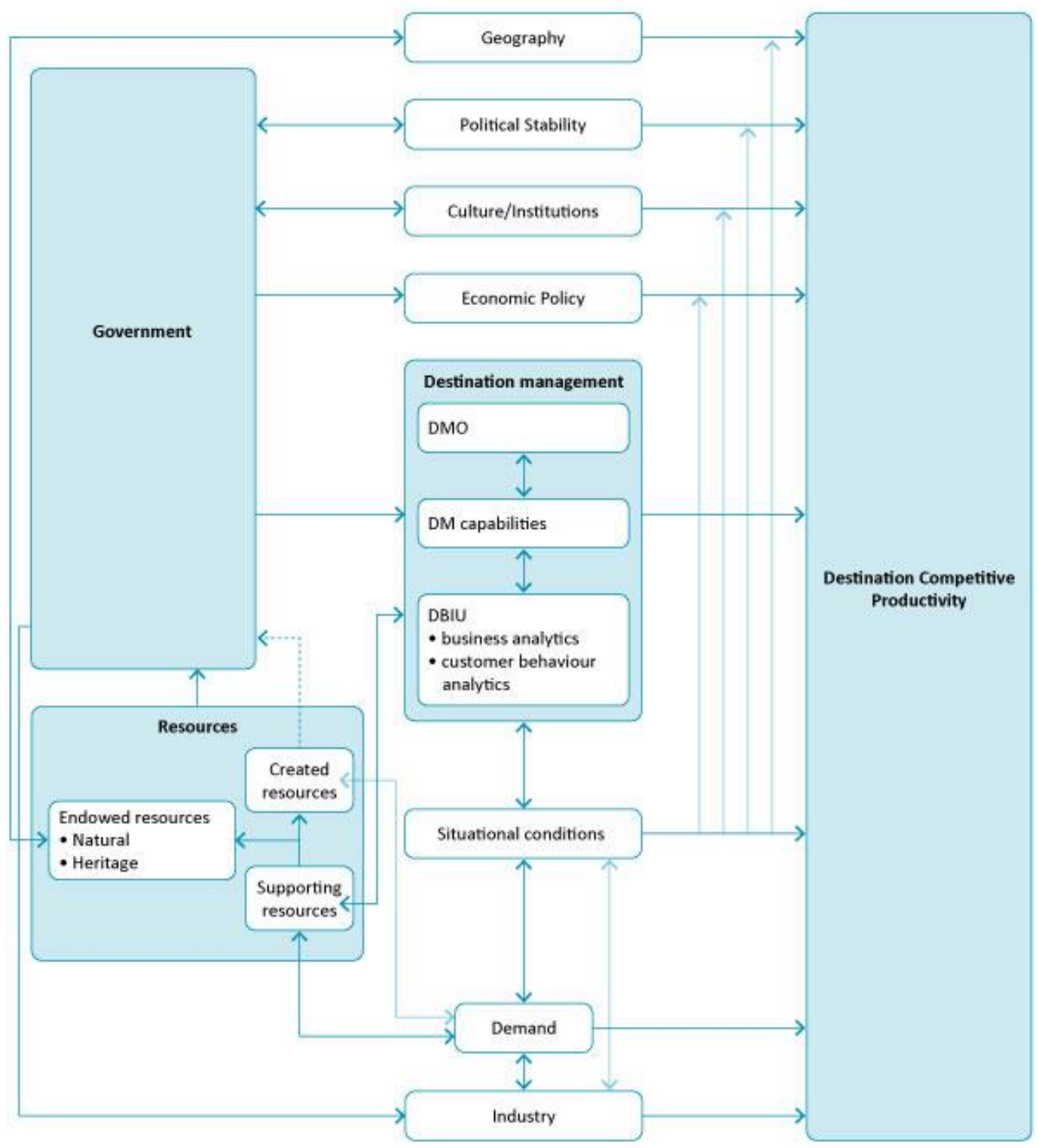

Figure 4. An integrative conceptual framework of Tourism Destination Competitive Productivity (TDCP)

Situational conditions, in line with Dwyer \& Kim (2003), affect both directly and indirectly (by impacting on demand, destination management, geography, political stability, culture/institutions and economic policy) the tourism destination CP. They encompass socioeconomic, technological, demographic, cultural, environmental, legal, and regulatory trends 
which influence the way tourism firms operate in the tourism destination. From the interviews it emerged that the way situational conditions are perceived can vary across the interviewees and sources, even though in this study we adopt a macro-level approach (focusing on policy makers and destination marketers) rather than a micro-level one. By recognizing that it is not always straightforward to separate situational conditions from government policy and market demand, we developed this category as it encompasses a number of trends and events that are not captured (or are marginally captured) by the other components of the framework. Examples of situational conditions mentioned by interviewees include: 1) the emergence of digital technologies and sharing economy platforms and their influence on tourists' consumption behaviors and patterns; 2) the way technological developments have been introduced into the operations of tourism and hospitality firms and transportation companies; 3) the relative strength of the destination currency; 4) constraints to public finances imposed by supernational treaties; 5) limitations to the free movement of goods and tourists that might be the result of higher costs for visa, embargos on goods, etc.; 6) natural disasters such as earthquakes, tsunamis, etc.; 7) terrorist attacks and wars.

As far as technological trends are concerned, it is emblematic what a destination manager of an Italian city destination said:

"Since 2012 the number of tourists in the city has increased considerably also thanks to the development and diffusion of accommodation-sharing sites like Aribnb. Airbnb allowed the destination to become more attractive and competitive for both domestic and international tourists, especially for the segment of tourists not willing to spend much money on a bed. It also allowed to meet the needs of several residents who have available space to rent...[...] Airbnb made non-traditional accommodation providers more productive as they could use more efficiently their properties and owned space, and also the room capacity of the destination was made more efficient." (Destination marketer, Italian DMO).

The way national and local authorities respond to technological trends can lead to further consequences as this French destination manager pointed out:

"Starting from July 2018, Airbnb has been collecting the tourist tax on the reservations. This allows us to track the hosts, checking if their flats have permissions, and get the taxes remitted once a year to the municipality on behalf of hosts. The city has agreed 
that a part of the tourism tax should be allocated to the DMO for destination marketing activities. This has paid off as we have seen more engagement with our destination marketing initiative. It's kind of a win-win situation: we are able to accommodate more tourists and we get financial resources that can be used to attract additional tourists. A virtuous cycle is activated." (Manager, French DMO).

Situational conditions also represent moderators. For instance, constraints in the form of indebtedness of a country, as well as weak public finances, can moderate the governmental influence on destination $\mathrm{CP}$ by means of economic policies. For instance, in a Portuguese destination:

"The liberalization of the property market has been a double-edged sword, because it has propelled the development of infrastructure for tourism which has attracted increasing tourism flows to the destination, but it has also priced out residents from the center of the city. Certainly, the destination has become more competitive because tourism demand has been increasing significantly for several years now and the labour costs have gone down in real terms over time. So, the liberalization has made our destination more competitive and our tourism firms more efficient and productive." (CEO, Portuguese DMO).

In this case, the liberalization was dictated by the situational condition of constraints to public finances imposed by supranational agreements (at the European level) which obliged Portugal to decrease its debt to GDP ratio. In parallel, the labour force did not receive increasing levels of protection, thus making the tourism industry more efficient and productive.

Moreover, governments can include tourism at the center of their development agenda, thus making destinations more appealing and cheaper:

"It's not easy to give a list of destinations that have a cost advantage in absolute terms. The price for the tourists depends on so many variables: the distance from the origin place, the season, the category of services that tourists choose, and so on. Turkey has been one of the cheapest destinations for European tourists for years thanks to the significant investment of the national government to increase transportation capacity by investing in infrastructure such as the "new" Istanbul airport and the enhancement of the national airline company Turkish Airlines. The government also supported 
entrepreneurs through incentives and income and corporate tax exemptions for tourism firms for almost a decade in destinations such as Istanbul and Antalya." (German destination marketing consultant)

Governments also largely shape the structure of the DMO and either directly or indirectly influence the destination managers. A former manager of the Czech NTO mentioned that complying with governmental regulations was one of the most relevant constraints for them and it could sometimes slow down entrepreneurial activities. In the recent past their major competitiveness factors have been a weak currency (compared to the Euro), a good tradition of hospitality and a relatively young and flexible class of tourism entrepreneurs. For this reason, they have been always considered a cheap destination, especially by Western European tourists. However, the manager commented that tourism enterprises are rather efficient, and this somehow helps make the destination more productive.

The sheer majority of the tourism policy makers and destination marketers/managers we talked to, clearly mentioned that digital technologies - more generally Industry 4.0 technologies and more specifically Big data and Analytics - are a key driver of tourism destination competitiveness because they help generate business analytics and customer/tourist behavior analytics conducive to business insights that are critical to shape value added services for both tourists and tourism firms. For instance, the destination marketer of a Dutch DMO observed:

"The municipality runs one of the most distinctive smart cities initiatives in Europe and the big data we collect with sensors and other devices throughout the city are allowing us to improve residents' quality of life, as well as offering opportunities to shape better services and mobility for tourists and visitors and avoid congestion. These big data feed a data dashboard which in turns feeds an app that provides information about the city's least known attractions. The app mixes the big data from sensors, smartphone GPS, and other tourism data and provides tourists with a compass rather than a map. It offers them the possibility to reach the specific attraction through alternative routes that allow to discover hidden gems that are off the beaten path. Therefore, tourists are spread more evenly across the city and they are more satisfied with their experiences. This way tourists and residents are happier, the destination improves carrying capacity management, and local tourism firms and attractions can 
serve their customers more effectively avoiding long queues. At the end of the day, all of the stakeholders benefit from the big data fed app, and the city's appeal and competitiveness are enhanced". (Dutch destination marketer).

Several other policy makers and destination marketers suggested that big data and analytics can help the tourism industry develop opportunities for efficiency gains, mentioning the role that big data from multiple sources are playing for hotel chains willing to reduce energy costs, as well as the role of multiple types of data for effective location marketing for restaurasnts and pubs, and especially the importance of big data to feed apps that allow businesses to create value added services and gain efficiency. For instance, the destination marketer of a British destination mentioned:

"Several restaurants in the city are now using the [name of app] which relies on large data from event advertisers, user generated content, transportation providers, and weather. They use it for local marketing to gain consumer insights, increase revenue and even optimize personnel shifts and raw produce costs. News and content related to events and weather data can help them modify the resource needs as they can gain a more accurate estimate of the number of patrons they could have a in certain day. Real time analytics feeding these app are allowing restaurants to keep the pulse of the demand and leave a waiter at home if s/he is not needed. This means more efficiency for the business overall and for the entire local industry."

Talking about a city in Northern Europe, a destination marketing consultant with expertise in the area shared that:

"The city DMO collaborates closely with the airport. The airport collects, processes, stores and analyses a huge amount of data from user generated content, smartphones, thousands of sensors, flight movements, information systems, images and transactions. There is a Data \& Analytics Expertise Center dealing with this big data and generating analytics to generate insights that help the airport and the entire destination to improve their operational and strategic decisions. The airport shares big data analytics with airlines, tour operators, handling companies, and transportation companies. It also offers APIs to airline companies to improve their operational performance and passenger satisfaction, to handlers to enhance their operational efficiency, to tour operators and transportation companies to improve their own travellers' apps and systems. Big data and analytics offer opportunities to the business ecosystem of the tourism industry and the entire destination to create value, enhance their 
competitive advantage and increase efficiency, and the destination is benefiting from this data immensely”.

The last case suggests that value from $\mathrm{BD}$ and $\mathrm{BDA}$ propagates throughout the value chains of the businesses of the entire destinations, and multiple stakeholders in the industry, thus influencing the capability of the destination to achieve higher levels of efficiency and effectiveness. Importantly, the DMO needs to possess destination management capabilities to make managerial sense of BD and BDA that are typically produced and or analyzed in partnerships with other destination stakeholders. Moreover, destination capabilities can also affect the degree of development of different forms of destination management information systems that work with BD and BDA to generate business intelligence. The BDA-enabled destination management information system is termed for the sake of convenience Destination Business Intelligence Unit (DBIU) and is illustrated in the ensuing subsection to unveil the role of $\mathrm{BD}$ and $\mathrm{BDA}$ in the tourism destination competitive productivity (TDCP) framework.

\subsection{Big Data and Analytics in the tourism destination Competitive Productivity (CP) framework.}

Based on existing models of information and data integration and management at the destination level - covered in the literature (e.g., Fuchs et al., 2014; Zeng et al., 2020) or emerging from our interviews (both reported in the previous subsection and in this subsection) - we can introduce and define the Destination Business Intelligence Unit (DBIU) and elucidate its role for destination management and for destination competitive productivity.

A Destination Business Intelligence Unit (DBIU) can be defined as a data and information platform endowed with data science hardware, software and capabilities - often integrated within a destination management organization (DMO) or a Convention and Visitors Bureau (CVB) - able to create sustained destination business intelligence which consists of analytics (exploratory, descriptive, predictive and prescriptive) built on multiple data coming from different and disparate sources that can help monitor in real time the progress of the tourism destination towards the achievement of business (and in the most advanced cases also socio-environmental) objectives.

It constitutes a broader and more advanced conceptualization of prototypical forms of destination management information systems (Fuchs et al., 2014) and smart destination systems (e.g., Zeng et al., 2020) illustrated in earlier literature, and is a focal hub for data retrieval, storage, processing, analysis, and reporting. The platform is endowed with Big Data 
and Big Data Analytics technologies (Rüßmann et al., 2015) to retrieve, collect, process, store, analyze, monitor, report and visualize in real time data streams (Cox and Ellsworth, 1997) related to business initiatives and impacts. To make it clear, there are no destinations that use the term DBIU: this is a generic term that we have coined and deployed to describe an advancement over prototypical forms of destination management information systems described in the literature (e.g., Fuchs et al., 2014; Zeng et al., 2020).

The platform is useful primarily for Destination Management Organizations (DMOs) to improve the attractiveness of the destination in terms of tourist arrivals and tourism expenditure (in a sustained way), and to monitor carrying capacity. Moreover, it is useful for the private sector and tourism enterprises to enhance their competitiveness. The data retrieved, collected, processed, stored, analyzed, monitored, reported and visualized can be made available also to other stakeholders (Freeman \& Reed, 1983; Freeman et al., 2010; Friedman $\&$ Miles, 2002) such as tourism policy makers, tourists and residents (Sautter \& Leisen, 1999), and other local and international stakeholders. At the moment of data collection, the most advanced projects to develop platforms with an architecture similar to the model of the DBIU were facing some difficulties in brining on the same page multiple stakeholders, as clarified by

"We position ourselves as a smart destination and have invested significantly over the last 3 years in improving our big data infrastructure and capabilities by working with [Vendor]. We collect in real time and process a large volume of data from multiple stakeholders including data collected through sensors, public transportation data, and several attractions. We are now starting to "fuse" these data with weather and traffic data to generate insights for tourism service providers. ...It is very challenging as we have to engage continuously with different stakeholders that share some of their data but would like to access all of the data from the other stakeholders. There is always a huge coordination effort and we have to persuade that everyone is sharing as much as they can." (Executive, Spanish municipal DMO)

In line with recent initiatives aimed at using Big Data Analytics to improve the decision making of destination managers and marketers (e.g., Fuchs et al., 2014; Höpken et al., 2020; Zeng et al., 2020) the DBIU combines and integrates device data (e.g., mobile roaming data, Wifi data, GPS data, etc.), transaction data (e.g., online booking data, web search data, etc.), and user generated content (UGC) data (e.g., online picture and text data) (Li et al., 2018) and 
deploys advanced methods and techniques such as Artificial Neural Network to predict tourist arrivals (Höpken et al., 2020), as well as expenditure. As explained by a consultant working for an Italian CVB:

"We realized that tourism product suppliers including tour operators, activity providers, museums, and ourselves, were not connected with tourist info points, hotels, the regional DMO and OTAs, and this prevented us from addressing rapidly the tourists needs and put them in contact with the right supplier. Therefore, we decided to invest in a platform that would allow suppliers to connect with resellers by leveraging both descriptive and predictive analytics. The analytics are generated from device data and UGC data. This has been an advancement over available destination marketing systems and allowed us to do a better job in understanding what is going on at the destination level” (Consultant, Italian CVB).

While the basic version of the DBIU is mainly focused on generating business and economic indicators, an increasing number of smart tourism initiatives (e.g., Zeng et al., 2020) are also contemplating the integration of transportation data (e.g., vehicular traffic), environmental data (e.g., weather data, $\mathrm{CO} 2$ emissions, water, gas and electricity consumption data, etc.) and public health data (e.g., epidemiologic data).

What are the most common forms of data transformed into BDA by the DBIU? While the main objective of the DBIU is to retrieve, process, store, analyze, monitor, report and visualize in real time data streams (Pigni et al., 2016), it can retrieve and analyze both structured and unstructured data. It leverages on data mining and Artificial Intelligence techniques (Pillai et al., 2021) that are applied mostly to specific forms of:

- transaction data such as web search data (Höpken et al., 2020), and online booking data (Fuchs et al., 2014);

- user generated content (UGC) data such as social media content (Marine-Roig \& Anton Clavé, 2015);

- device data such as Wifi data (Picco-Schwendener et al., 2019), and GPS data (Zhou et al., 2016).

Despite budget constraints, several of the destination managers interviewed are trying to invest in some forms of platforms that we termed broadly DBIUs. These platforms are posing a 
number of challenges to both DMOs and city managers. As this representative of a municipality dealing with tourism suggests:

"Today we are facing two big challenges. The first is understanding which data are worth collecting and which are not, and how much those data cover the destination. Transaction data are important but not all transactions are covered as many transactions are made with cash. The second issue has to do with the way we can make sense of the data we collect in a holistic manner. I mean, sometimes we have separate patterns that emerge: one from the airport arrivals and departures, one for the hotel room occupancy, one for the attractions and so on. This does not add much value. Combining these patterns to understand what is happening in the whole destination is instead more relevant for us. The first challenge cannot be addressed as far as I know. Regarding the second one, we have not internally the skills to deal with data fusion and commissioned to a technology vendor a feasibility study for an advanced smart destination marketing system that will allow us to combine the patterns from the airport, hotels and attractions data and generate both separate and integrated analytics." (Municipality representative, Spanish city)

Another challenge that emerged relates to the extent to which the analytics are actually transformed into insights conducive to innovation. For instance, an executive of a British DMO shared that:

"Data analytics without innovation of tourism products and services is pointless. We have established a business idea incubator to develop new products in line with the changing preferences and wants of our tourists and residents. We collect relatively large volumes of data from user generated content to understand tourists' preferences, then triangulate them with data from other sources, and try to give hints to tourism product providers on the trends that they should ride and the way a product could be tweaked" (Executive, British local DMO).

In line with data science paradigms (Han et al., 2011; Hofmann \& Klinkenberg, 2016; Witten \& Frank, 2002), data science techniques can be exploited to (i) retrieve data from varied sources, (ii) determine a quality dominant logic for data retention and management, (iii) define a model to homogenize such heterogenous data; (iv) combine data into aggregated forms 
suitable for further post-processing, and (v) report and visualize data. Among the data that the DBIU contributes to retrieve, there are also data related to customer behavior and engagement that can be extracted adopting variations on a theme of commercial software (e.g., Apache Hadoop) and other purpose-built software (e.g., software whose architecture was built to retrieve content from major tourism destination websites and their social media). Among the purpose-built software, a suitable tool has been developed to capture online tourists' behaviors from social media data: it consists of four modules: data extractor, parser, analyzer and visualizer modules (e.g., Mariani et al., 2016). Regardless of the software used, the DBIU might allow not only DMOs and destination marketers to collect and process a vast amount of heterogeneous data, but could also let DMOs share some of the relevant data related to customer behavior and customer perceptions in real time with local firms that provide accommodation, food and beverage, attractions, transportation services.

As clarified in the above definition, the proposed concept of DBIU plays a key role to harvest data feeding into sustained destination business intelligence which consists of analytics (exploratory, descriptive, predictive and prescriptive) built on multiple data coming from different and disparate sources. In particular, destination business intelligence addresses important and timely questions related to the economic (and in some cases environmental) challenges facing a tourism destination. Therefore, they answer questions such as: What Happened? What's happening? (destination-level descriptive analytics); Why did this happen? Why is this happening? (destination-level exploratory analytics); What will happen? (destination-level predictive analytics); How to optimize the future social and environmental situation? (destination-level prescriptive analytics).

The aforementioned destination-level analytics are described in the following matrix that reports the time and the intelligence value created (see Table 1).

\begin{tabular}{|l|l|l|}
\hline & Past/Present & Future \\
\hline Knowledge & $\begin{array}{l}\text { Destination-level } \\
\text { Exploratory analytics } \\
\text { Why did this happen? } \\
\text { Why is this happening? }\end{array}$ & $\begin{array}{l}\text { Destination-level } \\
\text { Prescriptive analytics } \\
\text { How to optimize? }\end{array}$ \\
\hline Data/information & $\begin{array}{l}\text { Destination-level } \\
\text { Descriptive analytics } \\
\text { What Happened? } \\
\text { What's happening? }\end{array}$ & $\begin{array}{l}\text { Destination-level } \\
\text { Predictive analytics } \\
\text { What will happen? }\end{array}$ \\
\hline
\end{tabular}

Table 1. DBIU business analytics 
As clear from the matrix, the bottom left quadrant reports destination-level descriptive analytics, the upper left quadrant destination-level exploratory analytics, the bottom right destination-level predictive analytics, the top right destination-level prescriptive analytics.

A number of stakeholders could benefit differently from DBIU analytics. In general, destination managers, tourism policy makers, urban planners, and tourism firms are interested in DBIU analytics, but the benefits that they can obtain from these analytics could be different. For instance, tourism policy makers and urban planners might make use of DBIU analytics to develop more informed policies and regulations based on real time insights relevant across a number of areas including carrying capacity, pollution, livability, transportation, etc. This is the case of a city situated in the Castile and León region of Spain that has invested significantly in IoT technologies and sensors capturing and generating vast amounts of data useful to monitor air quality and urban traffic that is conducive to improve tourism policies. DMOs might deploy DBIU analytics to understand the underlying motivations of consumption of tourism services by service type and help redefine the supply of those services based on the motivations identified. This is for instance the case of the DMO of a major city in Northern Italy which is deploying big data analytics developed by a research center connected with the local university to cluster museums' users conjointly with an analysis of subscribers' life cycle to minimize customers' churn. Tourism firms (such as hotels) can use DBIU predictive analytics to improve forecasting, given that forecasting allows better purchasing, more efficient staffing, etc. However, in many cases the analytics developed by (large) hospitality firms are especially tailored to the firm than DBIU analytics: for instance a couple of InterContinental hotels in San Francisco managed to reduce their energy costs by $10-15 \%$ by merging data from almost fifty sources entailing weather data, electricity rates, and energy consumption of buildings. Using a predictive algorithm helped them to decide whether to receive power from a grid or use an onsite battery module.

Overall, there are different enabling conditions associated with a DBIU in general and DBIU analytics in particular:

1) the first enabling condition is the presence of a data driven culture which is not necessarily common across DMOs, but it is becoming increasingly relevant. For instance, several leading municipal DMOs in Scandinavia and the UK that were already adopting Destination Marketing Systems have launched initiatives revolving around big data analytics as they already developed a data driven culture. A destination marketer of a British DMO mentioned: 
"Data is important, and we try to make decision based on both experience and data. We had already invested in a DMS and were already generating a few basic analytics enabling us to carry out customer micro-segmentation and optimize the online customer journey and experience. We have recently moved into more sophisticated analytics and we believe that this will allow us to generate important insights to create value for our tourists and residents."

2) the second enabling condition is the presence of financial resources to be allocated to a DBIU. Many low-funded DMOs suffer from severe budget constraints and cannot engage effectively in technology investments beyond those for basic digital marketing. Those DMOs that have traditionally allocated more financial resources to marketing research are also typically those that can afford investment in big data technologies or at least partner with the city council to buy or develop conjoint smart cities initiatives. A member of the tourism board of a Portuguese town said:

"We simply do not have enough financial resources to embark on big data analytics initiatives. We use all our budget for "traditional" digital marketing and some of the digital marketing activities are outsourced to a web agency."

3) the third enabling condition has to do with the capability of recruiting and retaining skilled human resources and talent possessing adequate analytical skills. Typically, skills are outsourced by DMOs which frequently rely on local research centers and universities (in most of the analyzed European DMOs deploying big data) and in some cases technology vendors (especially in Northern Europe). Moreover, it is more likely that DMOs might generate basic descriptive analytics, with predictive analytics being most of the times outsourced as suggested by a destination manager working for a municipal DMO in Portugal and another working for a local DMO in the UK. The member of the tourism board of an Italian city mentioned:

"We decided to support this initiative by taking on board the local university. They are adopting predictive analytics to track consumer behaviors of cultural initiatives in the city and also in the region. At the beginning they carried out pattern analysis based on spatial-temporal use of a museums' subscription. Later they used link analysis to describe and understand users' behavioral patterns. Right now, they are generating a model to optimize the revenues of the visited museums. This is adding relevant analytics that can be helpful also to inform hoteliers' decisions. Overall, this will allow us to better understand the 
underlying motivation of consumption for these leisure services and redefine the supply based on the motivation identified. At the end of the process the research center agreed to transfer to us the BDA methodology that they developed. However, I am not sure if we will have the skills to use it."

\section{Discussion and Conclusions}

\subsection{Conclusions}

Tourism destinations and tourist arrivals have experienced a sustained growth over the last seven decades and until January 2020 due to a coalescence of factors including the increase of the share of per capita GDP and time allocated to travel and leisure, advancement in transportation and digital technologies, improved protection of travelers' rights, and consumption shifts (UNWTO, 2019). However, while in the Fifties the top ten destinations in terms of international tourist arrivals were controlling two thirds of the market and were concentrated in Europe, currently they control less than a third of the market and a number of emerging national destinations especially located in the Asia-Pacific region have become increasingly more competitive (UNWTO, 2019).

As tourism destinations are facing increasing levels of competition over time, it has become imperative for tourism policy makers, destination managers and tourism researchers to identify and analyze the drivers of destination competitiveness. To address this need, a number of scholars (e.g., Crouch \& Ritchie, 1999, 2012; Dwyer et al., 2000; Dwyer \& Kim, 2003; Enright and Newton, 2004; Mihalič, 2000) have developed sophisticated tourism destination competitiveness frameworks starting from the 1990s. Those frameworks have identified and illustrated key factors enhancing the competitiveness of a destination.

Recently, research in the social sciences and information systems and management science, as well as computer science, has suggested that digital technologies are playing an increasing role in improving the governance and management of tourism destinations. For instance, destination management information systems (Benckendorff et al., 2014; Fuchs et al., 2014) and smart tourism destinations (e.g., Gretzel et al., 2015; Jovicic, 2015) research has focused on different technologies that might help destinations enhance tourism destination management, planning and development. More specifically, we recognize that the development and advancement of Big Data and Big Data Analytics is allowing destinations to build progressively more robust information systems able to assist decision making at the destination level and enhance the smartness of tourism destinations. Meanwhile, in the wider business 
field, the concept of Competitive Productivity (CP) has been introduced and developed (Baumann and Pintado, 2013; Baumann et al., 2019) to identify several key drivers of competitiveness and productivity at the macro level (besides the meso and micro levels).

In this work, we leverage both existing literature and empirical work (namely interviews and field work involving destination managers of Destination Management Organizations and Convention and Visitors Bureaus and further secondary data) to introduce, elaborate, develop, and present an integrative conceptual framework of tourism destination competitive productivity (TDCP) which blends together several features of established tourism destination competitiveness models (e.g., Dwyer \& Kim, 2003), the destination management information systems (Fuchs et al., 2014) and smart tourism destinations (e.g., Gretzel et al., 2015) research streams, and the framework of Competitive Productivity (CP) at the macro level (Baumann et al., 2019). This integrative framework suggests that a systematic approach should be taken to the analysis of tourism destination competitiveness drivers, thus implying that the key drivers (namely resources, demand, industry, destination management) identified in earlier tourism destination competitiveness frameworks (e.g. Crouch and Ritchie, 1999; Dwyer \& Kim, 2003) should be juxtaposed to other macro drivers (namely geography, political stability, culture and economic policy) identified in the CP framework (Baumann et al., 2019). In addition, we argue that in the aforementioned systematic approach Big Data Analytics promise to be a key driver of destination competitiveness as well as competitive productivity. Indeed, increased competition between destinations implies enhanced destination competitiveness (driven also by destination business intelligence), that will improve destination management quality (Van Reenen, 2011), which eventually will translate into increased productivity. In the ensuing section we illustrate the theoretical contributions of this work.

\subsection{Theoretical implications}

This work has made several contributions in the area at the intersection of competitive productivity, tourism destination competitiveness, big data and BDA for destination management and smart tourism destinations. First, to the best of our knowledge, this is the first study that has elaborated an integrative conceptual framework of Tourism Destination Competitive Productivity (TDCP) by blending the established destination competitiveness framework proposed by Dwyer and Kim (2003), the Competitive Productivity (CP) framework proposed by Baumann et al. (2019), and research on big data analytics in tourism and hospitality (Mariani et al., 2018a) relevant for destination management information systems (Fuchs et al., 2014) and smart tourism destinations (e.g., Gretzel et al., 2015). Secondly, we 
read closely the extent to which Industry 4.0 technologies are explicitly mentioned in tourism destination competitiveness work and realize that the most popular frameworks mention tangentially digital technologies. Accordingly, we contribute to the Industry 4.0 research stream in services (Mariani and Borghi, 2019) and service BDA (Akter et al., 2020), by underlying how Big Data and Analytics constitute propelling factors of the ongoing digital transformation of competitive tourism destinations and the services they offer. This way we offer a more systematic and technological innovation research-informed approach to the examination and analysis of the drivers of tourism destination CP in the context of the ongoing $4^{\text {th }}$ industrial revolution. Third, we contribute to both the destination management information systems (Fuchs et al., 2014) and smart destinations (e.g., Zeng et al., 2020) research streams by introducing and conceptualizing the Destination Business Intelligence Unit (DBIU). The DBIU is a data and information platform - which can take different forms across different tourism destinations - endowed with data science hardware, software and capabilities integrated within a destination management organization (DMO) or a Convention and Visitors Bureau (CVB) or part of a wider partnership within a smart destination - able to create sustained destination business intelligence which consists of analytics (exploratory, descriptive, predictive and prescriptive) built on multiple data coming from different and disparate sources and stakeholders that can help monitor in real time the progress of the tourism destination towards the achievement of economic goals and other types of goals. Interestingly, DBIUs seem to be important for destinations as they allow the DMO to disseminate key market and performance insights to its members almost in real time. This information, in line with what observed in a less digitized world twenty years ago "is essential to ensuring destination productivity and effectiveness" (Crouch and Rirchie, 1999: p. 149) and is becoming even more essential to adjust innovation processes at the destination level in real time. Accordingly, our work projects the aforementioned observation of renowned destination competitiveness scholars (i.e., Crouch and Rirchie, 1999) suggesting how industry 4.0 technologies (and their underlying "oil" of big data and analytics) can empower productive, efficient, effective and competitive tourism destinations. Fourth, while we recognize that the DBIU might now be a nascent and somehow asymptotic architectural concept to which many destinations are aspiring, it represents a clear advancement over more traditional destination marketing systems (Haines, 1994; Morrison, 2019) that mostly connect customers with service providers but do not support the generation of insights for broader destination management decisions involving more than mere customer data. Accordingly, this suggests that the concept of DBIU can be used as a meaningful construct in future destination management research to illustrate how 
digital technologies can support strategic decision making through business intelligence at the destination level, thus bridging two often disconnected chapters of destination management research: "digital marketing and ICTs" and "destination marketing planning" (Morrison, 2019). Last, we also contribute to the literature revolving around information systems within digital ecosystems and platforms (Nambisan, 2017), by suggesting that as the dominant economic, social, cultural and political institutions in society coevolve with the digital technologies underpinning the technological components of destination management in general, and more specifically the DBIUs, institutions and organizational stakeholders should be brought into the picture by information systems scholars and digital ecosystems and platforms researchers interested in gaining a more comprehensive understanding of how information systems can be leveraged to achieve and monitor tourism destination performance and competitiveness objectives.

\subsection{Practical implications}

This work bears several practical implications for tourism policy makers, destination managers and marketers, technology developers, as well as tourism and hospitality firms and practitioners.

As far as tourism policy makers are concerned, first they should increasingly recognize that supporting tourism destination competitiveness requires a holistic approach which sees tourism policies intertwined with other economic policies pertaining to other industries including transportation, energy, construction, etc. Secondly, tourism policy makers should become aware that digitization initiatives - and more specifically smart destination initiatives (e.g., Zeng et al., 2020) - should be prioritized in their agenda and allocated appropriate investment and resources. Third and linked to the previous point, they should make sure that the government lend the appropriate support to Destination Management Organizations and Convention \& Visitors Bureaus so that they can implement successfully big data analytics initiatives. Fourth, tourism policy makers should realize that DMOs can only create value conjointly with destination stakeholders (for instance tourism and hospitality firms) but have to make sure that the destination as a whole can appropriate a portion of that value. In some cases, a destination might need to partner with nearby destinations, and this needs to be pondered carefully to avoid sharing data that might compromise the focal destination's capability of transforming data into competitive advantage. In this case, tourism policy makers should warn tourism destination managers (e.g., DMOs) to share only a part of the analytics. Last, as the examples of some airport-led smart initiatives show, a constant flow of data and 
analytics from major access points can be conducive to the generation of value for the competitiveness of the entire destination and the efficiency of the tourism industry: accordingly, DMOs are encouraged to partner increasingly with airports embracing these type of initiatives.

Regarding destination managers and marketers, first they might build and make use of platforms such as the proposed DBIU to capture data streams in real time and use the deriving data analytics for a number of purposes related to improving the attractiveness of the destination (in terms of tourism flows and destination image), developing new products and services, launching targeted integrated communication marketing plans, leveraging social conversations on social media to improve digital advertising, modifying transportation options to decrease traffic. Second and related to the previous point, BDA should enable destination managers to share insights about business processes with the tourism industry, to ensure that the entire value system of a destination be integrated seamlessly, which implies an integration of organizational value chains to ensure that all business processes are effectively and efficiently managed: this could ultimately allow the tourism destination to achieve economies of scale and scope in the way its resources are used and deployed. Third, they should liaise with the government to make sure that smart destination initiatives be integrated as effectively and efficiently as possible within broader smart city initiatives. This implies also that there should be no duplications of smart initiatives and that the platforms through which they are implemented should be interoperable. Fourth, DMOs should allocate at least an employee (on a part- or full-time basis, depending on the size and complexity of the destination) to the development of the activities of the DBIU, namely the creation of sustained business intelligence by means of analytics. The employee should have a technical background (e.g., a background in data science or computer science) and possibly have some business knowledge of (or be passionate about) the tourism sector. While we observed that the larger DMOs have typically hired digital marketing specialists to cover these roles in the past, we see and expect that in the near future DMOs will look for more skilled employees in data science to internalize. Fourth, while currently aware of the importance of investing in nurturing BDA capabilities, CEOs of DMOs often face financial constraints that hinder several of their attempts to further develop platforms as similar as the DBIU. One of the possible solutions here might be to develop BDA capabilities conjointly with other city departments (e.g. transportation) that are typically endowed with more financial resources and use similar BDA for related purposes. For instance, GPS BDA and BDA capabilities to gain knowledge on current traffic and predict traffic in a tourism destination might be useful also for the DMO to improve the planning of 
tourists flows at the destination level and monitor carrying capacity. Fifth, to overcome technological liabilities, DMOs should increasingly partner with research centers and technology vendors that in many destinations cities across Europe are generating important insights through BDA to improve destination managers' decisions. These initiatives should not be circumscribed to a specific project but should be strategically developed over periods of 3-5 years as observed in two DMOs that have benefited from knowledge transfer initiatives of BDA.

As far as technology developers are concerned, first they need to understand that designing destination management information systems in general and more specifically DBIUs requires an in-depth analysis of the stakeholders that are going to contribute, share, control and use BDA. Second and related to the previous point, DBIUs should be developed as multi-stakeholder solutions under the guise of cloud-computing enabled SaaS platforms allowing the DMO to share data with focal stakeholders. Third, technology developers should make sure to sidestep technological barriers as not all partners might be endowed with the same information systems and technology. Accordingly, technology developers should work with DMOs to make sure that DBIUs are scalable and interoperable systems bringing together DMOs, governments, academic institutions, the civil society, and the private sector. Fourth, APIs should be made available to app developers to make sure that the amount of data about travellers, passengers and tourists can be used by local businesses at the destination to create personalized services for tourists and residents (Mariani et al., 2021).

In relation to tourism and hospitality firms and practitioners, first they should collaborate proactively with the DMO by sharing relevant information about bookings and reservations so that the destination business intelligence might be expanded. In exchange, firms and practitioners might obtain market research that might allow them to monetize better on extant products and services. Second, hospitality and tourism firms might leverage the destination business intelligence in real time (Pigni et al., 2016) to develop new products or variations of existing products, thus supporting their innovation activities. Third, they might juxtapose their own marketing analytics with the BDA generated by the DBIU to generate even smarter insights to improve customer micro-segmentation, and pricing decisions.

\subsection{Limitations and future research}

Even if the integrative framework put forward is not perfect, it helped a number of destination managers to understand how to effectively and efficiently manage a tourism destination. Several destination managers commented that the DBIU is somehow a platform 
that they have partially implemented through their smart destination initiatives. However, they believe that a further necessary step in the evolution of the DBIU should be to integrate analytics pertaining to socio-environmental dimensions and indicators (Mariani and Borghi, 2021). Consistently with a triple bottom line approach (Elkington, 1997; Norman \& MacDonald, 2004) to destination management, this further development might encourage future researchers to further conceptualizations of "integrative sustainable intelligence" (Silvestre and Fonseca, 2020). Furthermore, several dimensions of the framework necessitate additional work to improve its efficacy in a number of situations, including the ongoing public health crisis engendered by the Covid-19 pandemic. Consistently, an advanced version of the framework should incorporate explicitly big data analytics from epidemiologic and clinical data.

Overall, we observe that: i) the development and adoption of a DBIU are at different stages across tourism destinations and DMOs and this implies also that the amount of business intelligence accumulated at the destination level by means of big data analytics vary across destinations; ii) the magnitude of relevance of each of the drivers/variables of Competitive Productivity (CP) of a tourism destination has not yet been determined and the importance attached to each variable might vary across destinations; iii) the capability of the DBIU to support the competitiveness of the destination might be dependent on the BDA capabilities (Gupta and George, 2016) developed at the destination level, and this has to be measured by assessing tangible and intangible BDA resources as well as human resources; iv) as the framework is based mostly on primary data from European DMOs and CVBs and only secondary data from non-European destinations, in-depth empirical testing of the model should be performed across destinations from different geographical areas, especially by taking into account Asian destinations that are immersed in a different cultural milieu that could affect differently competitiveness (e.g., Baumann et al., 2016). Despite these limitations, we hope that this framework might contribute to our knowledge and understanding of tourism destination competitive productivity (TDCP) and how it is evolving in the digital age and in relation to one of the nine technologies underpinning the industry 4.0 (Kagermann et al., 2013). We expect that future research might further analyze how the enhanced CP of a tourism destination might translate into striking a balance between economic, environmental, cultural, and social objectives. 


\section{References}

Akter, S., Gunasekaran, A., Fosso Wamba, S., Babu, M. M., and Hani, U. (2020), "Reshaping competitive advantages with analytics capabilities in service systems", Technological Forecasting and Social Change, Vol. 159, 120180.

Bakıc1, T., Almirall, E., and Wareham, J. (2013), "A smart city initiative: the case of Barcelona”, Journal of the Knowledge Economy, Vol. 4 No. 2, pp. 135-148.

Batty M. (2013), "Big data, smart cities and city planning", Dialogues in Human Geography, Vol. 3 No. 3, pp. 274-279.

Baumann, C., Cherry, M., Chu, W., Cummings, L., Viengkham, D. and Winzar, H. (2021), "Editorial: Competitive productivity (CP): advancing the competitiveness paradigm”, Cross Cultural \& Strategic Management, Vol. 28 No. 1, pp. 1-18.

Baumann, C., Cherry, M., and Chu, W. (2019), "Competitive Productivity (CP) at macromeso-micro levels", Cross Cultural \& Strategic Management, Vol. 26 No. 2, pp. 118144.

Baumann, C., Winzar, H., and Viengkham, D. (2019), Confucianism, discipline, and competitiveness. New York: Routledge.

Baumann, C., Hamin, H., Tung, R., and Hoadley, S. (2016), "Competitiveness and workforce performance: Asia vis-à-vis the West”, International Journal of Contemporary Hospitality Management, Vol. 28 No. 10, pp. 2197-2217.

Baumann, C., and Pintado, I. (2013), "Competitive productivity", Journal of the Institute of Management Services, Vol. 57, pp. 9-11.

Becken S., Alaei A.R., Wang Y. (2019), "Benefits and pitfalls of using tweets to assess destination sentiment", Journal of Hospitality and Tourism Technology, Vol. 11 No. 1, pp. 19-34.

Benckendorff, P., Sheldon, P. \& Fesenmaier, D. (2014), Tourism Information Technology. Oxford: CABI.

Borghi M. and Mariani M.M. (2020), "Service robots in online reviews: Online robotic discourse", Annals of Tourism Research, 103036.

Buhalis, D., and Foerste, M. (2015), "SoCoMo marketing for travel and tourism: Empowering co-creation of value", Journal of destination marketing \& management, Vol. 4 No. 3, pp. 151-161.

Buhalis, D., and Law, R. (2008), "Progress in information technology and tourism management: 20 years on and 10 years after the Internet-The state of eTourism research", Tourism Management, Vol. 29 No. 4, pp. 609-623.

Buhalis, D. (2000), "Marketing the competitive destination of the future", Tourism management, Vol. 21 No. 1, pp. 97-116. 
Chen, S. and Lin, N. (2020), "Culture, productivity and competitiveness: disentangling the concepts", Cross Cultural \& Strategic Management, Vol. 28 No. 1, pp. 52-75.

Cox, M., Ellsworth, D. (1997), "Managing Big Data for scientific visualization”, ACM Siggraph, MRJ/NASA Ames Research Center, Vol. 5, pp. 1-17.

Crouch, G. I. and Ritchie, J.R.B. (2012), "Destination competitiveness and its implications for host-community QOL." In Handbook of tourism and quality-of-life research, 491-513. Dordrecht: Springer.

Crouch G. I. (2011), "Destination competitiveness: An analysis of determinant attributes", Journal of Travel Research, Vol. 50 No. 1, pp. 27-45.

Crouch, G. I., and J. R. Brent Ritchie. (1994), "Destination Competitiveness: Exploring Foundations for a Long-Term Research Program". In Proceedings of the Administrative Sciences Association of Canada 1994 Annual Conference. June 25-28, Halifax, Nova Scotia 79-88.

Crouch, G. I., and J. R. Brent Ritchie. (1999), "Tourism, Competitiveness and Societal Prosperity”, Journal of Business Research, Vol. 44 No. 3, pp. 137-152.

Crouch, G.I., and Ritchie, J. R. Brent. (1995), "Destination Competitiveness and the Role of the Tourism Enterprise", Proceedings of the Fourth Annual Business Congress, Istanbul, Turkey, July 13-16, pp. 43-48.

Davenport, T. H. (2014), "How strategists use "big data" to support internal business decisions, discovery and production”, Strategy \& Leadership, Vol. 42 No. 4, pp. 45-50.

Davenport, T. H. (2017), "How analytics have changed in the last 10 years", Harvard Business Review, June.

D'Aveni, R. A., Dagnino, G. B., and Smith, K. G. (2010), "The age of temporary advantage", Strategic management journal, Vol. 31 No. 13, pp. 1371-1385.

D'Aveni, R.A. (1994). Hypercompetition Managing the Dynamics of Strategic Maneuvering. Free Press, New York, NY.

Dwyer, L., P. Forsyth, and P. Rao. (2000), "The price competitiveness of travel and tourism: A comparison of 19 destinations", Tourism Management, Vol. 21 No. 1, pp. 9-22.

Dwyer, L., and C. Kim. (2003), "Destination competitiveness: Determinants and indicators", Current Issues in Tourism, Vol. 6 No. 5, pp. 369-414.

Economist (2018), “The battle for digital supremacy America's technological hegemony is under threat from China". Accessed 29.01.2021 at:

https://www.economist.com/leaders/2018/03/15/the-battle-for-digital-supremacy

Economist (2017), "The world's most valuable resource is no longer oil, but data", May 6, 2017. Accessed 30.01.2021 at: https://www.economist.com/leaders/2017/05/06/theworlds-most-valuable-resource-is-no-longer-oil-but-data. 
Elkington, J. (1997). The triple bottom line. Environmental management: Readings and cases, 2.

Enright, M. J., and J. Newton. (2004), “Tourism destination competitiveness: A quantitative approach”, Tourism Management, Vol. 25 No. 6, pp. 777-788.

Fosso Wamba, S., Dubey, R., Gunasekaran, A., and Akter, S. (2020), "The performance effects of big data analytics and supply chain ambidexterity: The moderating effect of environmental dynamism”, International Journal of Production Economics, 107498.

Fosso Wamba, S., Akter, S., Edwards, A., Chopin, G., and Gnanzou, D. (2015), "How big data can make big impact: Findings from a systematic review and a longitudinal case study, International Journal of Production Economics, Vol. 165, pp. 234-246.

Freeman, R. E., and Reed, D. L. (1983), "Stockholders and stakeholders: A new perspective on corporate governance", California Management Review, Vol. 25 No. 3, pp. 88-106.

Freeman, R. E., Harrison, J. S., Wicks, A. C., Parmar, B. L., and De Colle, S. (2010), Stakeholder theory: The state of the art. Cambridge University Press.

Friedman, A. L. and Miles, S. (2002), "Developing stakeholder theory", Journal of management studies, Vol. 39 No. 1, pp. 1-21.

Fuchs, M., Höpken, W., and Lexhagen, M. (2014), "Big data analytics for knowledge generation in tourism destinations - A case from Sweden”, Journal of Destination Marketing \& Management, Vol. 3 No. 4, pp. 198-209.

Gajdošík T. (2019), "Towards a conceptual model of intelligent information system for smart tourism destinations", Advances in Intelligent Systems and Computing, Vol. 763, pp. 6674.

Glaser B.G., and Strauss A.L. (1967). "The discovery of grounded theory: strategies for qualitative research", New York, Adline de Gruyter.

Grant, R. M. (1991), “Porter's 'competitive advantage of nations': an assessment”, Strategic Management Journal, Vol. 12 No. 7, pp. 535-548.

Gretzel, U., Sigala, M., Xiang, Z., and Koo, C. (2015), "Smart tourism: foundations and developments", Electronic Markets, Vol. 25 No. 3, pp. 179-188.

Gretzel, U., Werthner, H., Koo, C., and Lamsfus, C. (2015), "Conceptual foundations for understanding smart tourism ecosystems", Computers in Human Behavior, Vol. 50, pp. 558-563.

Gupta, M., and George, J.F. (2016), "Toward the development of a big data analytics capability", Information \& Management, Vol. 53 No. 8, pp. 1049-1064. 
Haines P. (1994), Destination Marketing Systems. In: Schertler W., Schmid B., Tjoa A.M., Werthner H. (eds) Information and Communications Technologies in Tourism. Springer, Vienna. https://doi.org/10.1007/978-3-7091-9343-3_9

Han, J., Pei, J., and Kamber, M. (2011). Data mining: concepts and techniques. Elsevier.

Hoadley, S. (2020), “The concept of competitive productivity (CP): a linguistic investigation", Cross Cultural \& Strategic Management.

Hofmann, M., \& Klinkenberg, R. (Eds.). (2016), RapidMiner: Data mining use cases and business analytics applications. CRC Press.

Höpken W, Eberle T, Fuchs M, and Lexhagen M. (2020), Improving Tourist Arrival Prediction: A Big Data and Artificial Neural Network Approach. Journal of Travel Research. doi:10.1177/0047287520921244

Huang, M.H., and Rust, R.T. (2018), "Artificial intelligence in service”, Journal of Service Research, Vol. 21 No. 2, pp. 155-172.

Ivars-Baidal J.A., Celdrán-Bernabeu M.A., Mazón J.-N., Perles-Ivars Á.F. (2019), "Smart destinations and the evolution of ICTs: a new scenario for destination management?", Current Issues in Tourism, Vol. 22 No. 13, pp. 1581-1600.

Jovicic D.Z. (2015), "From the traditional understanding of tourism destination to the smart tourism destination", Current Issues in Tourism, Vol. 22 No. 3, pp. 276-282.

Kagermann, H., Wahlster, W., Helbig, J., Hellinger, A., Stumpf, M.A.V., Treugut, L., Blasco, J., Galloway, H., Findeklee, U., 2013. Securing the future of german manufacturing industry: recommendations for implementing the strategic initiative INDUSTRIE 4.0. Final Report of the Industrie 4.0 Working Group.

Lopez de Avila, A. (2015), "Smart Destinations: XXI Century Tourism". Presented at the ENTER2015 Conference on Information and Communication Technologies in Tourism, Lugano, Switzerland, February 4-6, 2015.

Mariani, M. (2019), "Big data and analytics in tourism and hospitality: a perspective article", Tourism Review, Vol. 75 No. 1, pp. 299-303.

Mariani, M.M. and Baggio, R. (2012), "Special issue: managing tourism in a changing world: issues and cases", Anatolia, Vol. 23 No. 1, pp. 1-3.

Mariani, M.M. and Borghi, M. (2019), "Industry 4.0: A Bibliometric Review of its Managerial Intellectual Structure and Potential Evolution in the Service Industries", Technological Forecasting and Social Change, Vol. 149, 119752.

Mariani, M. and Borghi, M. (2021), "Environmental discourse in hotel online reviews: a big data analysis", Journal of Sustainable Tourism, Vol. 29 No. 5, pp. 829-848.

Mariani M.M., Matarazzo M. (2020), "Does cultural distance affect online review ratings? Measuring international customers' satisfaction with services leveraging digital 
platforms and big data", Journal of Management and Governance, doi: 10.1007/s10997020-09531-z

Mariani, M.M., Baggio, R., Fuchs, M., Höpken, W. (2018), "Business Intelligence and Big Data in Hospitality and Tourism: A Systematic Literature Review", International Journal of Contemporary Hospitality Management, Vol. 30 No. 10, pp. 3514-3554.

Mariani, M., Di Fatta, G. and Di Felice, M. (2018a), "Understanding customer satisfaction with services by leveraging big data: the role of services attributes and consumers' cultural background", IEEE Access, Vol. 7 No. 8580523, pp. 8195-8280.

Mariani, M.M., Mura, M. and Di Felice, M. (2018b), "The determinants of Facebook social engagement for national tourism organizations' Facebook pages: a quantitative approach", Journal of Destination Marketing and Management, Vol. 8, pp. 312-325.

Mariani, M.M., Borghi, M. and Okumus, F. (2020), "Unravelling the effects of cultural differences in the online appraisal of hospitality and tourism services", International Journal of Hospitality Management, Vol. 90, p. 102606.

Mariani, M. M., Di Felice, M., and Mura, M. (2016), "Facebook as a destination marketing tool: Evidence from Italian regional Destination Management Organizations", Tourism management, Vol. 54, pp. 321-343.

Mariani, M.M., Buhalis, D., Longhi, C. and Vitouladiti, O. (2014a), "Managing change in tourism destinations: key issues and current trends", Journal of Destination Marketing and Management, Vol. 2 No. 4, pp. 269-272.

Mariani, M.M., Baggio, R., Buhalis, D. and Longhi, C. (2014b), "Tourism management, marketing, and development: Volume I: the importance of networks and ICTs", pp. 1265, doi: $10.1057 / 9781137354358$.

Mariani, M.M. and Fosso Wamba S. (2020), "Exploring how consumer goods companies innovate in the digital age: The role of big data analytics companies", Journal of Business Research, Vol. 121, pp. 338-352.

Mariani, M. M., Styven, M. E., and Teulon, F. (2021), "Explaining the intention to use digital personal data stores: An empirical study", Technological Forecasting and Social Change, Vol. 166, 120657.

Marine-Roig E., Anton Clavé S. (2015), "Tourism analytics with massive user-generated content: A case study of Barcelona", Journal of Destination Marketing and Management, Vol. 4 No. 3, pp. 162-172.

Mihalič T. (2000), "Environmental management of a tourist destination: A factor of tourism competitiveness", Tourism Management, Vol. 21 No. 1, pp. 65-78.

Morrison, A. M. (2018), Marketing and managing tourism destinations. London: Routledge. 
Muller, J.M., Kiel, D., Voigt, K.I. (2018), "What drives the implementation of industry 4.0? The role of opportunities and challenges in the context of sustainability". Sustainability (Switzerland) Vol. 10 No. 1, 247.

Nam, D., Lee, J., and Lee, H. (2019), "Business analytics use in CRM: A nomological net from IT competence to CRM performance", International Journal of Information Management, Vol. 45, pp. 233-245.

Nambisan, S. (2017), "Digital Entrepreneurship: Toward a Digital Technology Perspective of Entrepreneurship", Entrepreneurship Theory and Practice, Vol. 41 No. 6, pp. 10291055 .

Neuman, L. W. (2007). Social research methods, 6/E. Pearson Education.

Norman, W., and MacDonald, C. (2004), "Getting to the bottom of triple bottom line", Business Ethics Quarterly, pp. 243-262.

Palatková, M., and Hrubcová, G. (2015), "Monitoring regional competitiveness using the BSC method: A case of the Czech national tourism organization". Czech Journal of Tourism, Vol. 3 No. 2, pp. 107-126.

Pearce, D.G.(1997), "Competitive destination analysis in southeast Asia", Journal of Travel Research, Vol. 35 No. 4, pp. 16-25.

Picco-Schwendener A., Jost Reinhold H., Cantoni L. (2019), ACM International Conference Proceeding Series, pp. 18-24.

Pigni, F., Piccoli, G., and Watson, R. (2016), "Digital data streams: Creating value from the real-time flow of big data", California Management Review, Vol. 58 No. 3, pp. 5-25.

Pillai, R., Sivathanu, B., Mariani, M., Rana, N.P., Yang, B., and Dwivedi, Y.K. (2021), "Adoption of AI-empowered Industrial Robots in Auto Component Manufacturing Companies", Production \&lanning \& Control, http://dx.doi.org/10.1080/09537287.2021.1882689.

Porter, M. E. (2009). The competitive advantage of nations, states and regions. Harvard Business School. Available at: https://www.hbs.edu/faculty/Publication\%20Files/20110707_Malaysia_vcon_b3574e10-758b-483f-b6c5-f7439d7c58e9.pdf

Porter, M. E. (1995), "The competitive advantage of the inner city", Harvard business review, Vol. 73 No. 3, pp. 55-71.

Porter, M. (1990), The Competitive Advantage of Nations. The Fee Press, New York.

Porter, M. E. (1985), The Competitive Advantage: Creating and Sustaining Superior Performance. New York: Free Press.

Porter, M. E. (1980), Generic competitive strategies. Competitive strategy. New York: Free Press. 
Ritchie, J. B., and G. I. Crouch. (2003), The competitive destination: A sustainable tourism perspective. CABI Publishing.

Ritchie, J.R.B., and Crouch, G.I. (2000), “The competitive destination: A sustainability perspective", Tourism Management, Vol. 21 No. 1, pp. 1-7.

Ritchie, J.R.B., \& Crouch, G.I. (2001), "Developing operational measures for the components of a destination competitiveness/sustainability model: Consumer versus managerial perspectives". In J.A.Mazanec (Ed.), Consumer psychology of tourism, hospitality and leisure (pp.1-17).Wallingford: CABI.

Ritchie, J. B. and Crouch, G. I. (1993), "Competitiveness in international tourism: A framework for understanding and analysis". World Tourism Education and Research Centre, University of Calgary.

Rusmann, M., Lorenz, M., Gerbert, P., Waldner, M., Justus, J., Engel, P., Harnisch, M. (2015), Industry 4.0: the future of productivity and growth in manufacturing industries. Boston Consulting Group $\quad 9 \quad$ Retrieved from. https://www.bcg.com/publications/2015/engineered_products_project_business_industr y_4_future_productivity_growth_manufacturing_industries.aspx.

Sautter E.T. and Leisen B. (1999), "Managing stakeholders: A tourism planning model", Annals of Tourism Research, pp. 312-328.

Sena, V., Bhaumik, S., Sengupta, A., and Demirbag, M. (2019), "Big data and performance: What can management research tell us?" British Journal of Management, Vol. 30 No. 2, pp. 219-228.

Shao J., Chang X., Morrison A.M. (2017), "How can big data support smart scenic area management? An analysis of travel blogs on Huashan”, Sustainability (Switzerland), Vol. 9 No. 12, 2291.

Silvestre W.J. and Fonseca A. (2020), "Integrative Sustainable Intelligence: A holistic model to integrate corporate sustainability strategies", Corporate Social Responsibility and Environmental Management, forthcoming.

Tallman, S., Jenkins, M., Henry, N., and Pinch, S. (2004), "Knowledge, clusters, and competitive advantage", Academy of management review, Vol. 29 No. 2, pp. 258-271.

UNWTO (2019). World Tourism Barometer 2019. https://www.unwto.org/world-tourismbarometer-2019-nov

Van Reenen, J. (2011), "Does competition raise productivity through improving management quality?", International journal of industrial organization, Vol. 29 No. 3, pp. 306-316.

Wise N., Heidari H. (2019), "Developing smart tourism destinations with the internet of things". Big Data and Innovation in Tourism, Travel, and Hospitality: Managerial Approaches, Techniques, and Applications, 21-29. 
Witten, I. H., and Frank, E. (2002), "Data mining: practical machine learning tools and techniques with Java implementations.” Acm Sigmod Record, Vol. 31 No.1, pp. 76-77.

Wu, J., Guo, S., Huang, H., Liu, W., Xiang, Y. (2018), "Information and communications technologies for sustainable development goals: state-of-the-art, needs and perspectives". IEEE Communications Surveys \& Tutorials, Vol. 20 No.3, pp. 2389-2406.

Xiang, Z., Tussyadiah, I., Buhalis, D. (2015), "Smart destinations: foundations, analytics, and applications", Journal of Destination Marketing and Management, Vol. 4 No. 3, pp. 143144

Zeng D., Tim Y., Yu J., Liu W. (2020), “Actualizing big data analytics for smart cities: A cascading affordance study”, International Journal of Information Management, Vol. 54, 102156.

Zhou Z., Dou W., Jia G., Hu C., Xu X., Wu X., and Pan J. (2016), “A method for real-time trajectory monitoring to improve taxi service using GPS big data", Information and Management, Vol. 53 No. 8, pp. 964-977. 